\title{
Peer education and HIV/AIDS: Past experience, future directions
}

Deanna Kerrigan

Ellen Weiss

Population Council

Follow this and additional works at: https://knowledgecommons.popcouncil.org/departments_sbsr-hiv

Part of the International Public Health Commons How does access to this work benefit you? Let us know!

\section{Recommended Citation}

Kerrigan, Deanna and Ellen Weiss. 2000. "Peer education and HIV/AIDS: Past experience, future directions," Horizons Report. Washington, DC: Population Council. 


\section{Hgrizons}

\section{Peer Education and HIV/AIDS: Past Experience, Future Directions}

Q Population Council

Horizons is implemented by the

Population Council in collaboration with

- International Center for Research on

Women (ICRW)

- International HIV/AIDS Alliance

- Program for Appropriate Technology in Health (PATH)

- The University of Alabama at Birming ham

- Tulane University 


\section{Peer Education and HIV/AIDS: Past Experience, Future Directions}

\section{Executive Summary}

Peer education typically involves training and supporting members of a given group to effect change among members of the same group.

Peer education is often used to effect changes in knowledge, attitudes, beliefs, and behaviors at the individual level. However, peer education may also create change at the group or societal level by modifying norms and stimulating collective action that contributes to changes in policies and programs.

Worldwide, peer education is one of the most widely used strategies to address the HIV/AIDS pandemic.

This report presents findings from a project designed to identify components and principles that influence HIV/AIDS peer education program quality and effectiveness, as well as gaps in and priorities for operation research. The project was coordinated by UNAIDS and the Horizons Project, ${ }^{1}$ and implemented with the Jamaican Ministry of Health, PATH, AIDSMark/PSI, IMPACT/FHI, and USAID. The project

\footnotetext{
${ }^{1}$ The Horizons Project is implemented by the Population Council in collaboration with ICRW, PATH, International HIV/AIDS Alliance, Tulane University, and the University of AlabamaBirmingham.
}

aimed to be a participatory and comprehensive analysis of the strengths and limitations of peer education, and included three phases: a needs assessment of peer education program managers, a literature review on the key topics identified by needs assessment participants, and an international consultation of 45 experts that was held April 18-21, 1999, in Kingston, Jamaica. Consultation participants included peer education program managers, peer educators, donors, and researchers representing Africa, Asia, Latin America and the Caribbean, North America, and Europe.

This project did not attempt to compare peer educators to other communication channels (e.g., health professionals) or peer education programs to other HIV prevention strategies (e.g., voluntary counseling and testing). Rather, given the importance of peer education programs worldwide and evidence from some studies of their effectiveness, the project set out to gather information from research and field experience to help strengthen peer education programs. What emerged were suggestions specific to peer education as well as those that have broader applications to other types of programs. 
The needs assessment identified nine topics as priority areas. Key findings and recommendations from the consultation on these nine topics are summarized below:

\section{Integration of HIV/AIDS Peer Education with Other Interventions}

Peer education generates demands for services in the intended audience. Therefore, it should be integrated with or linked to services that provide access to condoms, medical care, voluntary counseling and HIV testing, and STI management. Peer education should also be integrated, where possible, with community health and development initiatives. Peer educators are often more comfortable with integrated programming because they prefer being perceived as general community health educators rather than "AIDS educators" due to stigma. What and how to integrate must be based on an analysis of the peer educators' and the community's needs, the role of stigma in reaching key audiences, and the availability of human, organizational, and financial resources.

\section{Finding and Keeping Peer Educators}

The definition of a peer and the selection process for peer educators were found to vary across programs. Despite differences, consultation participants felt that peer education programs should create partnerships with the intended audience and other stakeholders to develop clear criteria for the selection of peer educators and a manageable scope of work. The need to provide peer educators with some kind of compensation was strongly recognized. Discussion centered on whether compensation should be monetary or non-salary incentives like t-shirts, bicycles, access to loans, free medical care, and/or the status of being a peer educator. Participants recommended that compensation be based on the availability of resources and contextspecific values and standards to avoid creating social distance between the peer educator and the intended audience. Peer educators called for increased responsibilities and decisionmaking authority as well as opportunities for personal and professional growth to improve job satisfaction, retention rates, and program sustainability.

\section{Training and Supervising Peer Educators}

During the consultation there was debate about the scope and length of training, with some advocating intense training on only a few critical topics and others promoting broad and comprehensive training. Participants did agree that peer educator training needs to focus not only on how to impart HIV/AIDS information but on participatory techniques that peer educators can use to engage the audience in problem-solving dialogue about behavior change and underlying gender and socioeconomic barriers. Peer educators 
should also be involved in the design of

training curriculum and support materials. In

addition, training should be competency-based

and ongoing with the aim of increasing

knowledge and skills over time. Supervision

of peer educators needs to take place in the

field as well as the office, and supervisors

need to be technically competent as well as

motivational and supportive.

\section{Gender, Sexuality, and the Sociocultural Context}

Consultation participants strongly recognized

the need for peer education programs to

address gender inequalities that affect

sexuality and HIV/AIDS transmission and

mitigation. But to do this, peer education

programs need materials for analyzing the

gender dynamics and attitudes of the

community, project staff, and peer educators

in order to increase understanding of the

relationships between socially defined gender

roles, sexual behavior, and HIV/AIDS.

Evaluation data also need to be analyzed by

sex to determine whether the outcomes of the

peer education program are different for males

and females in order to identify what, if any,

modifications in the program are needed. In

addition to gender, peer education programs

need to be particularly attentive to differences

in status, rank, and hierarchy that exist in

different environments such as the military,

factories, and brothels. These differences

should be assessed during the formative research phase, and peer education programs need to be sensitive to them when forming peer groups. Programs also need to determine when it is more appropriate to use persons with greater power or status for communicating certain messages rather than "true peers."

\section{Program Activities to Foster Behavior Change}

Peer educators should participate in formative research and program evaluation in order to inform the design and content of activities. Moving from imparting AIDS facts alone to fostering and sustaining behavior change in the intended audience involves reinforcing messages through different peer-educator-led or peer-educator-linked activities, such as street theatre, radio call-in shows, support groups, policy advocacy, community mobilization, and so on. Peer education programs also need to set realistic behaviorchange goals that reflect the challenges faced by the intended audience and where they are along the behavior-change continuum (e.g., pre-contemplation, contemplation, preparation, action, maintenance).

\section{Care for People Living with HIV/AIDS}

Responding to the growing number of people living with HIV/AIDS (PLHA) in their communities is one of the greatest challenges faced by peer education programs. Because of 
limited program experience, participants did not formulate a list of program

recommendations. They did however call for training curricula and materials that describe ways in which peer education programs can address the growing needs for care and support of those infected and affected by HIV/AIDS. In particular, they highlighted the need to better understand the roles PLHA can play as peer educators and how they can be best supported as peer educators.

\section{Stakeholders}

Stakeholders can be gatekeepers (e.g., government officials, brothel owners) as well as people who have a vested interest in the peer education program such as the intended audience. Since they are key to the success and the sustainability of the program, they should be involved from the design phase onward in order to address their concerns, needs, and priorities, and instill a sense of ownership of the program. Early involvement also helps peer education programs capitalize on stakeholders' potential contributions, such as financial and human resources. Peer education programs need to clearly establish how the program will benefit stakeholders in order to enlist their support. They also need to develop complementary interventions for educating and mobilizing stakeholders to support behavior change in the intended audience.

\section{Program Sustainability}

Peer education is regarded by some as an inexpensive program strategy because it often relies on volunteers. Yet the costs of implementing high-quality peer education can be high, due to the ongoing need for funds to adequately train, support, and supervise peer educators, and equip them with resource material. In addition, some kind of compensation for peer educators is crucial. Generating financial resources and support is critical to the sustainability of peer education programs. Examples of strategies that have contributed to sustainability include involving the intended audience and stakeholders in the peer education program and creating a sense of joint ownership; documenting program effectiveness and promoting the results to donors, stakeholders, and government; and generating income from condom sales, t-shirts, comic books, and interest from microcredit loans. Peer education programs need to develop short-, medium-, and long-term strategies for sustainability.

\section{Evaluation and Operations Research}

A review of the published peer-reviewed and non-peer-reviewed literature reveals some evidence of peer education's effectiveness in certain populations and contexts. When asked why they use peer education, participants stated that it is an effective strategy, although 
not all programs represented had outcome data to support their perception of peer education's effectiveness for their intended audience. There was tremendous interest among program staff in conducting operations research and being exposed to research findings about the effectiveness and costeffectiveness of peer education programs, and those that answer operational "how to" questions (e.g., How can PLHA be motivated and supported to become and continue as peer educators?). It was strongly felt that donors should provide sufficient funds for evaluation of peer education programs and that incountry research capacity should be better utilized and strengthened.

\section{Conclusion}

The process of conducting a needs assessment to identify topics of concern to program managers and peer educators worked well for developing the consultation agenda on HIV/AIDS peer education. Bringing together representatives from a wide range of peer education programs enabled consultation participants to share ideas across continents and cultures, deepen their understanding of critical programmatic issues, and affirm what they are doing well and what they need to do to strengthen their programs. Program managers and peer educators alike stated their commitment to broadening peer education from a strategy that focuses on providing information to one that addresses the diversity of determinants of behavior change through expanded dialogue, community mobilization, policy advocacy, and the provision of HIVrelated services.

To accomplish the research and program goals identified by this project, continued funding by donors and governments is needed.

Participants strongly felt that such investments are critical if continued strides are to be made in controlling the HIV/AIDS epidemic and mitigating its effects on families and communities. 


\section{Introduction}

Worldwide, peer education is one of the most widely used strategies to address the HIV/AIDS pandemic. Despite its popularity, there has been little documentation and analysis of the operational issues facing peer education program managers. This report presents findings from a project designed to better understand these issues in order to inform policies and programs related to HIV prevention and the care and support of people living with HIV/AIDS (PLHA). The project was coordinated by UNAIDS and the Horizons Project, ${ }^{2}$ and implemented in conjunction with the Jamaican Ministry of Health, PATH, AIDSMARK/PSI, IMPACT/FHI, and USAID. The specific objectives of the project were to identify peer education program components and principles that influence quality and effectiveness, as well as operations research gaps and priorities. The project aimed to be a participatory and comprehensive analysis of HIV/AIDS peer education programs to date and included three phases:

- A needs assessment of peer education program managers.

\footnotetext{
2 The Horizons Project is implemented by the Population Council in collaboration with ICRW, PATH, International HIV/AIDS Alliance, Tulane University, and the University of AlabamaBirmingham.
}

- A literature review on the topics deemed most important by needs assessment respondents.

- An international consultation of peer education experts to develop program and research recommendations.

This report is organized in four sections. The first section is an introduction to peer education and includes a discussion of its meaning and evidence of its effectiveness. The second section describes the methods used for the needs assessment, literature review, and consultation. The third section presents the results from the three phases by topic and includes programmatic recommendations and experiences from the field. The final section includes the key conclusions.

This project did not attempt to compare peer educators to other communication channels (e.g., health professionals) or peer education programs to other HIV prevention strategies (e.g., voluntary counseling and testing). Rather, given the importance of peer education programs worldwide and evidence from some studies of their effectiveness (see page 3 ), the project set out to gather information from research and field experience to help strengthen peer education programs. What 
emerged were suggestions specific to peer education as well as those that have broader applications to other types of programs. In addition, the authors wish to acknowledge that there are limitations to peer education, several of which are discussed in this report, therefore peer education may not be appropriate in all situations.

\section{Defining Peer Education}

Peer education is a popular concept that variously refers to an approach, a communication channel, a methodology, a philosophy, and/or an intervention strategy. The English term peer refers to "one that is of equal standing with another; one belonging to the same societal group especially based on age, grade or status." The term education ( $v$. educate) refers to the "development," "training," or "persuasion" of a given person or thing or the "knowledge" resulting from the educational process (Merriam Webster's Dictionary 1985). In practice, peer education has taken on a range of definitions and interpretations regarding who is a peer and what is meant by education (e.g., counseling, facilitating discussions, mobilizing for advocacy, lecturing, distributing materials, making referrals to services, and providing support) (Shoemaker et al. 1998; Flanagan et al. 1996). Peer education typically involves training and supporting members of a given group to effect change among members of the same group. Peer education is often used to effect change at the individual level, with the aim of modifying a person's knowledge, attitudes, beliefs, or behaviors. Peer education may also effect change at the group or societal level by modifying norms and stimulating collective action that contributes to individual change as well as changes in programs and policies.

\section{Behavioral Theory and Peer Education}

Peer education as a behavior-change strategy is based on both individual cognitive as well as group empowerment and collective action theories. For example, Social Learning Theory asserts that people learn by observing the behavior of others and that some serve as models who are capable of eliciting behavior change in certain other individuals (Bandura 1986). The Theory of Reasoned Action states that a person's perception of the social norms or beliefs that people important to them hold about a particular behavior can influence behavior change (Fishbein and Ajzen 1975). The Diffusion of Innovation Theory posits that certain individuals (opinion leaders) from a given population act as agents of behavior change by disseminating information and influencing norms in their community (Rogers 1983). Peer education draws on elements of each of these theories in its assumption that certain members of a given peer group (peer educators) can be influential in eliciting individual behavior change among their peers. 
The Theory of Participatory Education also has been important in the development of peer education programs (Freire 1970). "Participatory or empowerment models of education posit that powerlessness at the community or group level, and the economic and social conditions inherent to the lack of power are major risk factors for poor health" (Amaro 1995). Empowerment, according to Freire, results through the full participation of the people affected; through dialogue the affected community collectively plans and implements a response to the problem or health condition in question (Wallerstein 1988). Many advocates of peer education claim that this horizontal process of peers (equals) talking among themselves and determining a course of action is key to peer education's influence on behavior change.

\section{The Effectiveness of HIV/AIDS Peer Education}

In order to gain a better understanding of the effectiveness of HIV/AIDS peer education programs, a review of published studies was conducted. While hundreds of evaluations have been carried out, few involved rigorous research designs and the collection of behavioral and biological outcome data. For example, only one randomized controlled trial utilizing HIV incidence as an outcome measure was found in the literature (Katzenstein et al. 1998). The majority of the evaluations utilized a pre-test/post-test or posttest-only research design without a control group and HIV-related knowledge, attitudes, and practices as outcome measures.

Table 1 presents findings from some of the more rigorous studies found in both the published peer-reviewed and non-peerreviewed public health literature. These examples represent studies that utilized experimental or quasi-experimental designs and HIV-related risk behavior or STI/HIV incidence as outcome measures. It is important to point out that the table is an illustrative but not exhaustive list of studies that fulfill such requirements. Results are presented by intended audience, including factory workers, injection drug users, men who have sex with men, and people living with HIV/AIDS. All of the studies cited in Table 1 found that peer education had a positive impact on STI or HIV incidence and/or risk behavior, or health status, thus providing evidence of its value for HIV/AIDS prevention, care, and support. Consequently, this project sought to document and analyze the findings from both the research literature and field experiences to identify program components and principles that influence peer education's quality and effectiveness. 
Table 1: Examples of Effective HIV/AIDS Peer Education Programs Based on Controlled Trials

\begin{tabular}{|c|c|c|}
\hline $\begin{array}{l}\text { Study Authors, Location, } \\
\text { and Sample Size }\end{array}$ & Intervention Components & Key Results \\
\hline \multicolumn{3}{|l|}{ Factory Workers } \\
\hline $\begin{array}{l}\text { Katzenstein et al. } 1998 \\
\text { Zimbabwe } \\
(\mathrm{N}=2000)\end{array}$ & $\begin{array}{l}\text { HIV counseling and testing } \\
\text { plus peer education } \\
\text { (intervention arm) versus HIV } \\
\text { counseling and testing alone } \\
\text { (control arm). } \\
\text { Access to condoms and STI } \\
\text { management was offered to } \\
\text { both groups. }\end{array}$ & $\begin{array}{l}\text { HIV incidence in the } \\
\text { intervention arm was } 34 \% \\
\text { lower than incidence in } \\
\text { workers from the control arm } \\
\text { ( } 2.21 \text { vs. } 3.20 \text { per } 100 \text { person } \\
\text { years, } p=.036) \text {. }\end{array}$ \\
\hline \multicolumn{3}{|l|}{ Injection Drug Users } \\
\hline $\begin{array}{l}\text { Rietmeijer et al. } 1996 \\
\text { United States } \\
(\mathrm{N}=1997)\end{array}$ & $\begin{array}{l}\text { Peer education plus distribution } \\
\text { and discussion of intervention } \\
\text { kits containing condoms and } \\
\text { bleach bottles (intervention } \\
\text { arm) versus no-intervention } \\
\text { control group. }\end{array}$ & $\begin{array}{l}\text { In contrast to the control } \\
\text { group, participants from the } \\
\text { intervention group reported } \\
\text { significant increases in } \\
\text { consistent bleach use (OR } \\
2.6 ; p<.001 \text { ) and consistent } \\
\text { condom use with occasional } \\
\text { partners (OR } 13.6 ; p<.001) \text {. }\end{array}$ \\
\hline \multicolumn{3}{|c|}{ Men Who Have Sex With Men } \\
\hline $\begin{array}{l}\text { Kelly et al. } 1997 \\
\text { United States } \\
(\mathrm{N}=438)\end{array}$ & $\begin{array}{l}\text { Peer education and HIV/AIDS } \\
\text { materials distributed by } \\
\text { popular opinion leaders in gay } \\
\text { bars in four intervention cities. } \\
\text { Educational materials only } \\
\text { were placed in bars in four } \\
\text { control cities. }\end{array}$ & $\begin{array}{l}\text { Unprotected anal intercourse } \\
\text { in last } 2 \text { months (baseline } 1.68 \\
\text { occasions; follow-up } 0.59: \mathrm{p}= \\
0.04 \text { ) decreased and condom } \\
\text { use during anal intercourse } \\
\text { increased significantly } \\
\text { (baseline } 44.7 \% \text {; follow-up } \\
66.8 \%, p=0.02 \text { ) in } \\
\text { intervention cities only. }\end{array}$ \\
\hline \multicolumn{3}{|l|}{ People Living with HIV/AIDS } \\
\hline $\begin{array}{l}\text { Gifford et al. } 1998 \\
\text { United States } \\
(\mathrm{N}=71)\end{array}$ & $\begin{array}{l}\text { Peer-led group sessions to } \\
\text { improve disease self- } \\
\text { management in patients with } \\
\text { symptomatic HIV/AIDS } \\
\text { (intervention group) versus a } \\
\text { usual care control group. }\end{array}$ & $\begin{array}{l}\text { Symptom severity index } \\
\text { decreased among members of } \\
\text { the intervention group and } \\
\text { increased among members of } \\
\text { the control group } \\
(-0.9 \text { vs. }+0.5 ; p<.03) \text {. }\end{array}$ \\
\hline
\end{tabular}




\section{Methods}

\section{Needs Assessment}

A needs assessment was conducted to develop a consultation agenda responsive to the needs of those working in peer education. The needs assessment also helped to identify potential participants who could participate in the international consultation. Interviews were conducted with a purposive sample of 30 peer education program managers from Africa, Asia, Latin America, and the Caribbean, identified by a large network of AIDS communication specialists. Program audiences included youth, female and male sex workers and their clients, industrial workers, the military and police, men who have sex with men, people living with HIV/AIDS (PLHA), and the general population. Many organizations reported reaching more than one population group. Respondents were asked about the reasons for selecting peer education as a strategy, the challenges they faced in program implementation, the changes they would like to make to their peer education program, and the topics that should be discussed at the consultation to address their needs.

\section{Literature Review}

A literature review was then conducted that focused on the following nine topics that were identified by needs assessment respondents as priority areas:

1. Integration of peer education with other interventions

2. Finding and keeping peer educators

3. Training and supporting peer educators

4. Gender, sexuality, and the sociocultural context

5. Program activities to foster behavior change

6. Care and support of PLHA

7. Stakeholder involvement

8. Sustainability

9. Evaluation and operations research

The studies and programs cited in the literature review came from the peer-reviewed literature (e.g., journal articles) as well as non-peer reviewed publications (e.g., conference abstracts and program reports). The results of the needs assessment and literature review were produced as a background paper for the consultation. ${ }^{3}$

\footnotetext{
${ }^{3}$ Copies of the paper, "Peer Education and HIV/AIDS: Concepts, Uses, and Challenges" can be obtained by contacting the Information Centre, UNAIDS, 20 Avenue Appia, 1211, Geneva 27, Switzerland, Email: (unaids@unaids.org) or by visiting their website (www.unaids.org).
} 


\section{Consultation}

The International Consultation on Peer

Education and HIV/AIDS was held April 18-21, 1999, in Kingston, Jamaica. The first two days

of the consultation were dedicated to

presentations by the participants and discussion

of the nine priority topics identified by the

needs assessment. On the third day, participants

split into working groups in which they

identified programmatic and research

recommendations for each topic. Participants

then presented and discussed these

recommendations at a final plenary session.

The agenda for the consultation can be found in Appendix 1.

Forty-five program managers, peer educators, and researchers representing governmental and nongovernmental organizations from Africa, Asia, Latin America, the Caribbean, North America, and Europe participated in the consultation. Participants represented a wide array of intended audiences, including youth, sex workers, factory workers, the military and police, men who have sex with men, PLHA, and prisoners (see Appendix 2 for a list of participants). The participants included the key informants who participated in the needs assessment and those they recommended, including peer educators. In addition, evaluation experts, communication specialists, donors, and the organizing partners of the consultation attended. 


\section{Findings}

The key findings from the needs assessment, literature review, and consultation are integrated and presented for each of the nine topics listed on page 5 .

\section{Integration of HIV/AIDS Peer Education with Other Interventions}

The vast majority of organizations participating in the needs assessment reported that their institution had integrated peer education with other program activities in an effort to prevent HIV infections and provide care and support to PLHA. Examples of complementary activities included condom distribution; social marketing; counseling; STI/HIV testing and support services, information, education, and communication (IEC) campaigns and materials; drama/theater; policy advocacy; home/hospice care; and orphan support. While most respondents stated that their peer education programs were integrated with other interventions, several informants stressed that it was their peer educators who linked these program activities and services together. Needs assessment informants were interested in knowing which combination of components best complement peer education in order to increase overall program effectiveness as well as to respond to a demand for services. Many informants were particularly interested in learning how to utilize advocacy strategies to modify the legal and social systems that influence HIV risk behavior. Several informants also reported that their institutions had begun to integrate HIV/AIDS peer education activities into broader health and development programs in reproductive health, violence prevention, substance abuse, life skills training, microcredit, and community development. Many informants were interested in learning more about these types of "crossover" experiences that link HIV/AIDS peer education programs with other health and development initiatives.

The literature also demonstrates that peer education is often implemented in tandem with other HIV prevention program components such as condom distribution and/or STI testing and treatment services (Kathuria et al. 1998; Katzenstein et al. 1998; Morisky et al. 1998). Moreover, the literature reflects the growing recognition of the complexity of the causal determinants of HIV infection and the need for interventions that address HIV-related behavior change on multiple levels -- individual, relational (e.g. partner, family), environmental (e.g. community, institutions) and structural (e.g. legal, political, economic). This shift towards multi-level prevention strategies has been documented in a number of papers calling for the design and evaluation of interventions 
that address environmental and structural constraints to preventive behavior in addition to individual attitudinal and behavioral factors that have traditionally been the focus of HIV/AIDS peer education programs. (Sweat and Denison 1995; Lurie et al. 1995; Tawil et al. 1995; Coates and Collins 1997). Little information is available in the literature, however, regarding what other interventions best complement HIV/AIDS peer education programs.

During the consultation, participants discussed the need to establish HIV/AIDS peer education as the foundation of larger-scale community mobilization and empowerment initiatives and expressed concerns about the limitations that some donors place on the range of activities that can be implemented with donor funding. Participants called for integrated programming and funding in order to address the complex and interdisciplinary causes of HIV infection in their intended audiences. But some participants expressed concern that program integration could lead to loss of focus, quality, and impact for peer education programs if limited resources are spread too thin. However, others stated that their intended audiences feel more comfortable with integrated programming that deals with HIV in the context of other health and development issues. Some participants also stated that their peer educators feel more comfortable with integrated programming that promotes their identification as a general community health educator rather than an
“AIDS educator" because of stigma and community acceptance. Overall, participants suggested that finding a balanced approach to program integration that increases access to HIV-related services and that fosters community development must be based on the specifics of a given cultural context and involve clearly articulated strategies for service delivery. The following programmatic recommendations emerged from the discussions:

- Because HIV/AIDS peer education generates demands for services in the intended audience, it should be integrated with or linked to basic services such as access to condoms, medical care, voluntary counseling and HIV testing, and STI management.

- To reduce structural barriers to HIV prevention, peer education should also be integrated with or linked to, where possible, community development initiatives (e.g., literacy, vocational/livelihood skills training, microenterprise and microcredit programs).

- Whether and how to integrate HIV/AIDS peer education with other services and programs should be based on a situation analysis that explores the willingness of peer educators and the community to integrate, the role of stigma in reaching key audiences, and the availability of human, organizational, and financial resources to offer complementary services. 


\section{Program Integration: Experience from the Field}

At the consultation, Dr. S. Jana (program manager) and Ms. Sikha Das (peer educator) from the Sonagachi sex worker project of West Bengal, India, presented examples of how this peer-led project has integrated different activities since its inception as a predominantly HIV/AIDS-focused program. By working from a community development and mobilization perspective, the need to integrate HIV/AIDS peer education with such other initiatives as violence prevention, legal services, and income generation arose from the sex workers themselves. Over time the sex workers have organized themselves and formed their own decision-making body that now guides program activities. In addition to HIV/AIDS peer education, this union of sex workers fights to protect sex workers from organized violence and for the legalization of sex work in India via community outreach and policy advocacy. The project has also formed a cooperative society to support savings and provide loans to sex workers to promote their economic rights and development.

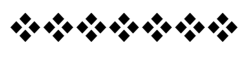

\section{Finding and Keeping Peer Educators}

Selecting peer educators who are acceptable to both program staff and community members and retaining them was identified as a key challenge by needs assessment informants. Several also expressed interest in learning how other peer education programs are able to retain their educators through either monetary or nonmonetary compensation and other forms of motivation.
The USAID-funded AIDSCAP program sponsored a workshop in 1995 to review peer education program experiences in Africa, which revealed that selecting and keeping peer educators was one of the most crucial components affecting program success (AIDSCAP 1996). Additional AIDSCAP research documented the importance of the following peer educator characteristics as part of selection criteria: confidence, technical competency, communication skills, and compassion (Flanagan and Mahler 1996). The European guidelines for youth peer education programs note that peer educators must be acceptable to and respected by the intended audience, with a personality conducive to training and suited to the work (Svenson 1998). One selection strategy that is becoming popular is the use of nomination techniques and social network analysis to determine which members of the intended audience would make the best peer educators. This involves talking to members of a given group to identify whom they would feel most comfortable talking to and receiving messages from about HIV-related issues. In the United States, such strategies have been used by HIV prevention programs among men who have sex with men (MSM) and injection drug users that have shown evidence of effectiveness (Kelly et al. 1997; Latkin et al. 1996). The literature also highlights the need to be aware of heterogeneity within a given peer group and the potential need for different types of peer educators to address such diversity. For 
example, a study conducted in the Dominican

Republic found five sexual identity groups

within the MSM community, as men

distinguished themselves as "cross-dressers,

homosexuals, gigolos, bisexuals, and

heterosexuals." Results of the study

demonstrate the need for peer educators from

and special HIV-prevention messages for each

of the distinct self-identified peer groups

(Sanchez and Arredondo 1996).

The definition of a "peer" was discussed at the consultation and participants debated in what ways peer educators need to be similar to their intended audience to be considered peers (e.g., age, sex, educational level, or place of residency). Participants also discussed whose decision it should ultimately be to define and select peer educators. From the discussions it became apparent that definitions of and hence the selection process for peer educators varied across program sites and depended on the intended audience and the sociocultural context. Also discussed was the challenge of recruiting peer educators in contexts where the behavior of a given peer group may be illegal or highly stigmatized, such as sex work or injecting drug use. In such a scenario, participants suggested close coordination with government in order to gain official acceptance for the project and not jeopardize the safety of the peer educators and the intended audience.
With regard to keeping and motivating peer educators, the issue of compensation emerged. All participants recognized the need for compensation, given that most peer educators come from poor communities and have limited time to volunteer because of their home and work responsibilities. Participants discussed the challenge of generating resources to provide adequate compensation and whether it should be monetary payment for services rendered or other forms of non-salary incentives like tshirts, bicycles, per diem, access to loans, free medical care, and the status of being a peer educator. Several participants questioned which type of compensation strategy would be more cost-effective for programs in the long term in light of the costs associated with drop-outs and training. Some participants suggested a tier system whereby the level and form of compensation given to a peer educator would be determined by his or her level of responsibility, quality of performance, and time contributed to the project. In additional to material incentives, participants highlighted the need for psychological and emotional support for peer educators who are often exposed to stressful situations. Overall, participants agreed that the identification of selection criteria, compensation, and scope of work need to be context-specific and clearly articulated.

To further explore the issues of peer educator retention, job satisfaction, and performance, a special session was held to hear from peer 
educators on these topics. Peer educators

stressed the need to be involved in project

development, decision-making and evaluation

as well as the importance of providing

opportunities for professional growth in order to

sustain their participation in the program. Their

suggestions and those from the other

consultation participants pertaining to finding

and keeping peer educators are included in the

following list of programmatic

recommendations:

- Create partnerships with the intended audience and other stakeholders to select peer educators.

- Develop and utilize clear criteria for the selection of peer educators.

- Design a manageable scope of work for the peer educator to improve retention rates.

- Offer compensation based on contextspecific standards and values. Make sure compensation given to peer educators is not so great as to create social distance between them and the peers they are trying to reach.

- Assure peer educators ongoing access to program material, resources, and updated information.

- Conduct periodic individual and group support sessions with peer educators to address stress, burnout, and other psychological aspects as well as to share successes and ideas.

- Provide peer educators with responsibilities and decision-making power in the design, implementation, and evaluation of the program.

- Create personal and professional growth and development opportunities within the organization for peer educators.

- Develop a plan to gradually pass control and maintenance of the program to "peers" and the community.

\section{Finding and Keeping Peer Educators: Experience from the Field}

During the consultation, Lediana Marfuru from the Iringa NGO Cluster of the Tanzania AIDS Project reported on the selection criteria used by her organization. The program's peer educators must be residents of the intended audience's community, acceptable to and respected by the community, sensitive to the values of the community, able to communicate effectively and educate others, able to maintain confidentiality, and a strong role model for the behavior he/she seeks to promote with others. She also stressed that peer educators should be answerable to their community rather than the project. Mahesh Dev Bhattarai from General Welfare Pratishan in Nepal discussed the problems of recruiting peer educators from highly mobile populations, such as sex workers. In response, the project also recruits less transient "near peers" such as the women who run the small restaurants out of which the sex workers ply their trade. Nguyen Thanh Son from Vietnam reported on incentives used by his organization's program with sex workers, including small loans, free medical care, and gifts to their children on special occasions. In addition, peer educators are encouraged to talk about their work to mass media and make presentations at local and national meetings, which increase their self-esteem. 


\section{Training and Supervising Peer Educators}

Needs assessment informants described several challenges to training both peer educators and technical/supervisory staff, such as insufficient funds for both initial and ongoing training. Several informants said that low levels of formal education of certain peer educators necessitated additional training, but that it was often not available. According to others, peer educator training needs to be more practical and participatory in nature and structured curriculum and support materials are absolutely necessary. As one informant stated,

The nature of training that is given to peer educators is abstract. They are trained in hotels with flip charts but when they go to the community they find a totally different scenario. They are unable to fully put in practice what they have been taught for they don't have the teaching aids for demonstration and materials to distribute.

Informants were specifically interested in the use of participatory training methods and communication skills-building exercises to sustain peer educator motivation.

Needs assessment informants also noted the difficulties in training supervisory and/or technical staff. According to one informant who is the program manager of a sex worker project,

Training of peer education technical staff is not as simple as ensuring that they know how to teach people about HIV. Peer education implies a philosophical vision in terms of respect for the population and trying to see things from their perspective, in our case from the lens of poor and marginalized women who live under conditions of violence and dependency. The staff training process often raises issues of race, gender, and class. We need to facilitate a consciousness-raising process among our staff so that they can manage not only the methodology and the content of the program but also the theoretical concepts behind it, and this may involve reviewing and changing some of their attitudes. If we do not work on these issues within ourselves as a staff, the whole educational process can be distorted.

In terms of follow-up and supervision, peer education was described as a "highmaintenance" intervention strategy requiring "high-quality coordination, leadership, and supervision." Other informants agreed, stating that the peer education approach relies heavily on part-time peer educators and coordinators who often need close supervision. Several informants expressed the need for resources to train more head office staff that could supervise peer educator activities in the field.

In its peer education guidelines, AIDSCAP suggests that training should begin with an assessment of participants' background and experience in HIV/AIDS education before the content of the training is decided. Critical elements of peer educator training include a clear definition of the educators' expected role(s) and sufficient opportunities to practice presentations on key topics, as well as time to develop skills for correct condom use or needle hygiene. Training should also involve a written or oral exam at the end of training in order to 
assess competency before fieldwork begins.

The level of support and supervision extended to peer educators should depend on the type of activities they are doing and the amount of training they have had in these areas. In general, regular meetings with peer educators on both an individual and a group basis are recommended as are observations of peer educators during their work, progress reports submitted by them, and evaluations of peer educators' performance by supervisory staff. Refresher training, updated information, materials, and staff retreats are also recommended (Flanagan and Mahler 1996).

During the consultation, participants debated the necessary scope and length of peer educator training. Some advocated for intense training in only a few critical topics while others stated that training should be broader and more comprehensive. The need to design a standardized process for identifying training needs and developing training programs was voiced. Several participants stressed the importance of providing peer educators with classroom training, followed by opportunities to practice what they learned in the field and then by classroom review. The fact that several welldeveloped HIV/AIDS peer education training and program curricula already exist that can be adapted to local needs was mentioned. But several participants discussed their concerns that many training programs for HIV/AIDS peer educators focus primarily on "AIDS facts" and not enough on how people in the community change HIV risk behavior. Participants emphasized that HIV/AIDS peer educator training needs to focus not only on how to transfer facts to their intended audience, but also on participatory techniques that peer educators can use to engage the audience in problemsolving dialogue about behavior change and underlying gender and socioeconomic barriers. This type of training combined with adequate supervision and support requires a substantial investment in human and financial resources. In order to improve peer education training, consultation participants made the following recommendations:

- Peer educators should be involved in the design or adaptation of training curriculum and support materials. This helps to ensure the relevance of the training and ownership of the program.

- In addition to HIV/AIDS transmission and prevention, peer education training should address sexuality and gender, interpersonal and group communication skills, and legal and ethical issues.

- Peer education training, as well as support and supervision, should be ongoing. The aim should be to increase knowledge and skills over time.

- Training should be competency-based and include initial and ongoing evaluation of competencies. 
- Training should take into account the personal development of the peer educator.

- Supervision of peer educators' performance should include both field and office-based supervisory sessions.

- Program staff who supervise peer educators must be technically competent as well as motivational and supportive.

\section{Training and Supervising Peer Educators: Experience from the Field}

Francisco Cartagena, a consultation participant, described Fundación Guadalupe's experience developing a peer education program for soldiers in El Salvador. He noted that small group sessions were a key element of the training and support provided to peer educators. After an initial four-day training, peer educators continued to meet in small groups in their barracks, sharing their experiences and clarifying questions about HIV/AIDS and educational and motivational strategies to use with their peers. He also mentioned the usefulness of having a theoretical framework to guide the training of peer educators. In their case, they used "Cadena de Cambios" (Chain of Changes), developed by the Academy for Educational Development, which encourages participants to identify determinants of risk behavior and then work through what can be done to change them.

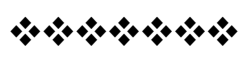

\section{Gender, Sexuality and the Sociocultural Context}

Gender refers to widely held beliefs about the roles, responsibilities, and decision-making authority that are appropriate and possible for males and females in a given society. A genderbased approach to HIV/AIDS peer education takes into account the ways in which gender norms influence HIV vulnerability, ability to adopt protective behavior, and the care and support of PLHA (UNAIDS 1998; Weiss and Gupta 1998). Several informants from the needs assessment discussed their desire to integrate a gender perspective into their organization's HIV/AIDS peer education programs. The issue of how to address gender roles and relations that undermine communication and the practice of safe sexual behavior was identified as a critical challenge to peer education programs and an agenda item for the consultation. Respondents questioned how to integrate gender theory and analysis into peer educator training and educational activities. Informants also spoke of the challenge of communicating about sex and sexuality in cultural contexts where such subjects are often taboo and provoke fears on the part of the community, parents, or religious groups that an open discussion of sexual topics may lead to promiscuous behavior. Some informants also stated that community prejudices held against sex workers and men who have sex with men influenced their program's ability to effectively implement activities. In general, informants recognized the influence of sociocultural norms and values on the success of peer education programs and stated that more consideration should be paid to the interrelationships among gender, sexuality, and stigma. 
A number of examples that describe how

HIV/AIDS peer education programs have addressed gender and sexuality were found in the literature. For example, in Brazil, female adolescent peer educators helped develop a booklet entitled "The Story of Maria" for use with peer groups during nine weekly sessions. The booklet addresses family and community pressure to maintain virginity, male pressure to have sex, and a girl's own internal pressures and desire for autonomy. The booklet also models boyfriend-girlfriend communication and mother-daughter communication, illustrating how to overcome barriers for girls in talking to partners, peers, and families about sex. By addressing these issues, the curriculum helped "young women make informed decisions about becoming sexually active outside of marriage and to question traditional gender roles about virginity and its relationship to sexual risk" (Vasconcelos et al. 1997).

In Sri Lanka, male and female youth peer educators facilitated discussions with peer groups about virginity, sexual behavior, and decision-making first in same-sex and later in mixed-sex group sessions. Findings showed that single-sex group sessions helped young women develop a public voice, which enabled them to actively participate in subsequent group discussions with males. The study also found that recruitment and retention of participants in these group sessions was greater for females then for males (Silva et al. 1997).
In Thailand, both female and male peer educators were trained to facilitate single-sex and mixed-sex group sessions with unmarried factory workers. Findings from formative research were used to "create comics and storybooks that included male and female characters whose attitudes and behaviors reflected prevailing gender norms about communication, sex and HIV prevention." Preand post-intervention interviews with participants demonstrated increased understanding of how traditional gender roles inhibit HIV-related communication as well as increased peer and partner communication on HIV/AIDS and sexual risk reduction (Cash et al. 1997). The study also found that young women were more able to "express an opinion and ask questions in girls-only HIV/AIDS peer education groups as compared to mixed-gender groups," which highlights the importance of special learning environments and messages for women (Busayawong et al. 1996).

Sociocultural values and norms that stigmatize sexual orientation, line of work (sex work), and behavior (drug use) also impact the ability of HIV/AIDS program planners to implement effective HIV/AIDS peer education programs. For example, deep-rooted biases against men who have sex with men have had a profound impact on the level of prevention and services for MSM in South Asia. Because of cultural, religious, and social reasons, male-to-male sexual behaviors are to a great extent invisible, 
often difficult to access and not framed within heterosexual and/or homosexual dichotomized constructions. Because of (such) social stigmatization, invisibility, and denial there are almost no HIV/STI services focused on MSM or dealing with anal sex behaviors... with there being almost no effective or appropriate research conducted on the subject (Khan 1997). It is within this context that the Naz Foundation has helped local NGOs develop peer-led "buddy systems" based on the natural social networks of MSM in South Asian countries such as India and Bangladesh. This approach has facilitated the identification, education, and mobilization of distinct sub-populations within the larger MSM community (Khan 1997).

During the consultation, participants discussed whether and how to address gender inequalities that affect HIV transmission. A large majority of participants stated that HIV/AIDS prevention programs should address gender bias directly and emphasized their intent to work not only with adult women but also with men and adolescents. In order to address this issue, participants asserted that peer education programs must obtain support from gatekeepers who influence sexuality and gender roles in the community, fostering frank dialogue between men and women about sexually sensitive topics, and creating access for younger people to programs and services.
In addition to gender norms, there is a larger set of social rules based on status and hierarchy that influence the behavior of individuals.

Participants discussed the importance of differences in status and provided specific examples of settings where peer education programs should be particularly attentive to rank and hierarchy, such as military and maritime environments, factories, and brothels. Participants noted that a peer education program need be cognizant of when and how to use true peers versus persons who have greater power and/or status for communicating which messages. For example, adolescents may feel more comfortable discussing certain topics with their peers and other topics with a health professional. The programmatic recommendations that emerged from the consultation about gender, sexuality, and sociocultural context were the following:

- Develop or adapt materials for gender analysis that help communities and project staff understand the relationship between gender and HIV/AIDS. This is important for identifying the gender dynamics of the community and negative attitudes among peer educators and other staff that may perpetuate gender biases.

- Gender inequalities should be addressed by developing or linking peer education programs with complementary interventions that empower women and improve their status such as literacy 
programs, income generation activities, and promotion of women's legal rights.

- Evaluation data should be analyzed by sex to determine whether the impact of the intervention is different for males and females in order to identify which genderrelated modifications in the peer education program are needed. Programs should also measure changes in gender beliefs and attitudes as part of program evaluation.

- Internal status differences within the intended audience should be assessed during the formative research stage. Peer group segmentation should be sensitive to differences in rank, hierarchy, and gendersexual identities.

\section{Gender and Sexuality: Experience from the Field}

At the consultation, Luis Moreno from the Center for Orientation and Integrated Research (COIN) spoke about his organization's peer education program which works with the sex worker union, MODEMU, in the Dominican Republic to create and maintain a network of peer educators within the country's female sex work industry. All training and educational programs begin with a participatory workshop to explore the sex workers' condition of poverty and marginalization and the relationship between these conditions to profound gender inequities in society, including the limited access to educational and economic resources for women. COIN's peer education program helps sex workers regain their self-esteem and assert themselves in the area of sexual decision-making by challenging societal definitions of the status and role of women and by creating opportunities for personal and professional growth.

\section{Program Activities to Foster Behavior Change}

Needs assessment informants expressed interest in learning about different types of program methodologies and activities to promote and foster HIV-related behavior change. For example, several informants questioned how a peer education program might vary its strategy and activities to reflect diversity (e.g., age, class, ethnicity, religion, and/or education) in the intended audience. Informants also discussed methodological issues related to group educational activities, such as how to help peer educators stimulate group discussion and learn about HIV/AIDS as well as "allow for the intended audience to come to its own conclusions and decisions" about overcoming barriers to prevention and care in the community. Key informants also expressed interest in learning about innovative and participatory methods to communicate HIV/AIDS prevention and care information as well as to maintain and motivate the interest of both the peer educators and their intended audiences.

The literature review uncovered many examples of programs that stated that they use "participatory methodologies" in their peer education programs. However, the specific methodological approaches were not often mentioned or clearly described in their papers or reports. Examples of participatory approaches that were mentioned in the literature included 
community mapping, picture codes, role playing, and interactive exercises (Kathuria et al. 1998; Schapink et al. 1998; Rietmeijer et al. 1996). The literature also highlighted the importance of skill-building activities as a component of peer education programs. For example, a randomized controlled trial involving MSM in the United States tested the differences in HIV risk behavior among men who received peer-led safer sex educational sessions plus skill-building and negotiation practice (intervention) as opposed to those who received only peer-led safer sex educational sessions (control). Participants that received both educational and skills building sessions increased their use of condoms in anal intercourse over a 12-month period by 44 percent as compared to 11 percent in the control group (Valdiserri et al. 1989).

In discussing how best to foster behavior change, consultation participants clearly articulated the need for PE programming to begin with a formative research phase that allows for full community participation and responds to the intended audiences' needs and interests. They also stressed the importance of using non-didactic, participatory techniques to engage the intended audience. There was much discussion about the need for a structured curriculum. Some participants questioned whether it was necessary for peer education program content and activities to be standardized into a set curriculum. On balance, participants expressed the need for an organized curriculum but recognized that it should be flexible and culturally appropriate. Some participants argued that the range of peer education activities should be unlimited and integrated into the daily lives and setting of the intended audience whenever possible rather than conducted as traditional healthtalks. Several participants also felt that peer education programs need to expand and diversify program activities to include innovative communication activities such as street theater and radio programming as well as peer-led advocacy efforts. Participants also highlighted the importance of setting realistic behavior change goals for peer educators that reflect the challenges faced by the intended audience and where they are along the behavior-change continuum (e.g., contemplation, preparation, action, maintenance). Finally, consultation participants articulated the need for peer educators to participate in ongoing program evaluation because of their field experience and insights into where people are along the behavior change continuum. Participants finalized their discussion on HIV-related activities and content to foster behavior change with the following recommendations:

- Peer education program design and content should be informed by formative research that involves the intended audience and other program stakeholders. 
- The extent to which the peer education curriculum (activities and content) is standardized should be determined by the needs of the intended audience.

- Messages should be reinforced through different activities and intervention channels.

- Peer education programs should adjust methodology and content to incorporate results from ongoing monitoring and evaluation that includes input from peer educators.

\section{Activities to Foster Behavior Change: Experience from the Field}

In his presentation at the consultation, Jeff Kawana, a peer educator from the Society for Family Health/PSI in Zambia described a peer-led youth-to-youth radio show as one of the organization's multiple, reinforcing interventions for communicating HIV prevention messages to young persons. The show hosts are peer educators who take calls from youth listening to the show around the country. However, the show does not limit its range of activities and content to HIV/AIDS. Instead, the program has found that by engaging the audience with popular music and addressing other issues of importance to youth, such as dating and relationships, HIV prevention issues come out in the discussion and are then highlighted naturally, making the audience feel more comfortable with the topic.

\section{Care and Support for People Living With HIV/AIDS}

All of the organizations represented in the needs assessment used peer education for HIV prevention but only a few were currently working with peers to provide or facilitate care and support for PLHA. Many informants stated that due to an increasing number of infected individuals, care and support were becoming priority issues within their organizations. Thus, many expressed interest in learning how to integrate care and support for PLHA into current peer education training and educational curriculum

Several descriptions of peer education programs involving PLHA were found in the literature and reflect a diversity of ways in which PLHA are being trained and subsequently engaged to educate and provide care and support to others infected with and affected by HIV/AIDS. Examples ranged from training courses for PLHA to learn how to provide counseling, support, and treatment information, such as one developed in Calgary, Canada (Maclaren-Ross and Baker 1998), to a peer education program in New York State that trains PLHA to take on leadership roles for policy advocacy, service planning, and decision-making (Tietz et al. 1998), to a community-based program in Vietnam that trains PLHA on care and support and stigma reduction. The trained volunteers educate other infected individuals as well as family, community members, and caregivers 
(Figueroa et al. 1998). In addition, The AIDS Support Organization (TASO) in Uganda has worked with PLHA peer educators to promote risk reduction among those already infected in order to prevent further infections as well as to sensitize both peers and community members to the issue of stigma and HIV/AIDS (Nakawunde and Ekwaru 1998).

Consultation participants discussed the involvement of PLHA as peer educators to provide and facilitate access to care and support for infected and affected individuals and families. Several stated that responding to the needs of the growing number of PLHA in their community by expanding their organization's range of services has been one of their biggest challenges. Another challenge has been finding and keeping PLHA peer educators, given the stigma associated with HIV status disclosure and the debilitating toll the disease takes on the health of the HIV-positive peer educator. An additional challenge is considering the role for PLHA in areas such as home care, given that such situations may expose PLHA peer educators to opportunistic infections that can jeopardize their own health. Because of limited program experience in this area, participants did not formulate a list of program

recommendations. They did, however, call for training curricula and materials that describe ways in which peer education programs can address the growing need for care and support of PLHA.

\section{Care and Support to PLHA: Experience from the Field}

Elizabeth Torres from the Self-Support Group for Women and Children (GAMI) in Cali, Colombia described how the organization uses PE to provide care and support to women and children living with HIV. GAMI provides a sense of community for women and children living with HIV/AIDS as well as workshops and support sessions on HIV/AIDS-related treatment options, nutrition, occupational health and income generation, family acceptance and relationships, and child care. By promoting empowerment and human rights, GAMI helps HIV-positive women support each other to regain control over their own lives and to effectively support their children.

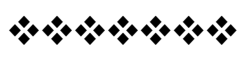

\section{Stakeholder Involvement}

Needs assessment participants identified a range of stakeholders, gatekeepers, and interest groups as important to the functioning of their peer education programs such as police, organized crime, teachers, brothel owners and/or industry managers. Several informants stated that such stakeholders and gatekeepers often create obstacles to program implementation. As one key informant stated, "The main challenge of utilizing peer education with factory workers is convincing factory administrators to accept the process and foresee the advantages of PE activities in the long run." Informants stated that support from stakeholders and gatekeepers was of primary importance in many environments, such as factories or brothels, due 
to restrictions that make it difficult for outsiders

to organize and implement educational activities. Several informants also described their frustration in working and coordinating with government agencies due to ill-defined or nonexistent policies regarding their key audiences as well as bureaucracy or lack of funding for programming. However, they also recognized the importance of gaining government support for program success. Other informants spoke of the challenge of developing a rapport with the community in general and with specific community stakeholders who can facilitate the implementation and acceptance of program activities. Thus, several informants recommended that techniques on how to involve and negotiate with program stakeholders be included in the consultation agenda.

There is some documentation in the literature of the importance of stakeholders as key persons who can facilitate and support access of PE programs to their intended audiences in order to effectively implement educational activities. For example, a PE intervention trial conducted in Zimbabwe cited the commitment, support, and cooperation of senior factory management as a critical factor contributing to the effectiveness of the intervention and documented the need for a government policy urging the private sector to adopt HIV prevention programs such as peer education. The program discovered that factory owners were willing to bear much of the cost of sustaining peer education once they realized the cost-saving benefits of decreasing HIV in their workplaces (Katzenstein et al. 1998).

The literature also addresses how stakeholders can influence behavior change among the intended audiences of PE programs. For example, the Superstar and Model Brothel programs of Chiang Mai, Thailand, combined both PE and policy advocacy by training sex workers as peer educator "superstars," motivating brothel owners to insist on mandatory condom use, and lobbying the Thai government to provide condoms. The proportion of sex workers refusing sex with clients who refused to use condoms increased from 42 percent to 78 percent over a period of one year after the combined intervention strategy was implemented (Visrutaratna et al. 1995).

Consultation participants debated the definition of a stakeholder. Some participants included members of the intended audience and peer educators in their definition of a stakeholder while others described stakeholders as persons outside of a given peer group with influence upon that group (e.g. gatekeepers). Despite some variation in definition, all participants agreed that stakeholders such as government officials, community leaders, teachers, brothel owners, factory managers, and members of the intended audience are important to the success and sustainability of PE programs. Participants 
stated that the early involvement of stakeholders in program design and development would help

PE programs capitalize on stakeholders' potential contributions to the project, such as financial and human resources. Additionally, their early involvement may prevent them from creating obstacles to program implementation because their needs and concerns were not originally considered by the project.

Consultation participants emphasized the need for stakeholders to join in both partnership and ownership of the peer education program with the intended audience and the implementing agency. They also discussed the challenges of how best to motivate stakeholders as well as negotiate their role and contributions to the program. Participants specifically highlighted the importance of government officials as stakeholders because of their ability to provide political cover and legitimacy to peer education programs. Additionally, government officials have the ability to incorporate project findings into national policies and institutions allowing for the local and regional scale up of peer education programs.

In addition to having an influence on program implementation and replication, some stakeholders can also have a profound effect on the intended audience's behavior. For example, brothel owners generally have a strong influence on the sexual behavior of sex workers. Given this dynamic, participants stressed the importance of targeting stakeholders in order to promote and sustain behavior change in the intended audience. Both of these potential roles for stakeholders in HIV prevention activities are reflected in the following program recommendations:

- Conduct a stakeholder analysis with the participation of the intended audience to identify who can facilitate the implementation of the peer education program.

- Clearly establish how the peer education program will benefit stakeholders and what is needed from them for program success and sustainability.

- Ensure that stakeholders have a sense of ownership in the peer education project through early involvement and ongoing consultation.

- Utilize stakeholders to promote and defend the peer education program.

- Develop complementary interventions to educate and mobilize stakeholders to support behavior change in the intended audience. 


\section{Involving Stakeholders: Experience from the Field}

Wantana Busayawong and Porntip Chuamanochan from Chiang Mai University have been coordinating an HIV/AIDS peer education program among northern Thai factory workers for the past several years. Over time, program staff involved several key stakeholders: factory managers, to gain their acceptance and physical access to the factories where restrictions make it difficult for outsiders to enter; and the Thai Ministry of Health, industrial councils, and unions, to garner contributions of both financial and human resources. They credit the involvement of key stakeholders for the peer education program's sustainability and success in increasing the adoption of protective behaviors among this population. Similarly, Grace Delano from the Association for Family and Reproductive Health in Nigeria credits their work with a wide variety of stakeholders for the scale-up of an HIVrelated youth peer education program. The stakeholders they targeted were youth, teachers, parents/guardians, professional associations, government organizations, youth-serving NGOs, and parent-teacher associations. Key strategies included building networks and coalitions among stakeholders, gathering evidence to spur action, and using the media to publicize the peer education program and its growing support.

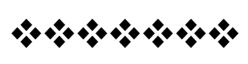

\section{Program Sustainability}

Lack of financial resources was cited by many needs assessment informants as a critical challenge to program implementation and continuity. Several informants maintained that peer education programs need to generate income, thereby contributing to their financial sustainability. A few specifically expressed interest in learning how to develop complementary microcredit programs through which loans can be made to peer educators as an incentive and the interest generated by these loans can be used for peer education program costs.

Despite the fact that HIV/AIDS peer education programs rely heavily on unpaid or low-paid field staff, peer programs still need to continually generate funding for peer educator incentives, professional/supervisory salaries, educational materials, training costs, and office space and equipment. Yet few examples of how to contribute to financial sustainability were found in the literature. Some HIV prevention programs have sought to generate income for peer education activities via clinic fees and condom sales (Rosario 1998), while other programs have tried to promote sustainability by integrating peer education training and education into the curriculum of existing institutions such as the military or schools (Upadhyay 1998).

Consultation participants referred again to the importance of involving the community, including the intended audience and stakeholders, in all aspects of the program to create a sense of joint ownership and responsibility for its sustainability. Participants also noted the need to network and market their peer education programs in order to secure a 
diverse pool of donor funding. Procuring donor funding is often dependent on an organization's ability to document program effectiveness and provide a concrete plan for financial sustainability. Several participants articulated the need for close partnerships with government in order to promote project sustainability, but many also noted the need to be realistic about certain government agencies' funding limitations and their bureaucratic constraints. Others asserted that HIV/AIDS peer education should be supported by government as part of their commitment to providing health care as a basic human right. With regard to what peer education programs can do to foster financial sustainability independent of government, participants mentioned a number of incomegenerating activities such as the sale of condoms, T-shirts, and comic books, as well as microcredit projects. The following program recommendations were identified by consultation participants regarding peer education program sustainability:

- Document peer education program effectiveness and promote the results to donors, stakeholders, and gatekeepers.

- Create partnerships among the community, NGOs, and government to share resources, responsibilities, and ownership of the peer education program.

- Develop institutional short-, medium-, and long-term strategies for programmatic and financial sustainability.

\section{Sustaining Peer Education Programs: Experience from the Field}

Odette Eiger from Women Against AIDS in Côte d'Ivoire described one way this NGO is helping to sustain its PE activities. Small loans are given to women in the community, and interest collected on these loans is channeled into the PE program fund. Providing women access to credit contributes to the continuity of peer-led educational activities and the social and economic empowerment of women, which can help reduce their vulnerability to HIV/AIDS. Verna Mzezewa described the factors contributing to the sustainability of the Zimbabwe AIDS Prevention Project's PE program in Harare factories. She noted that a workplace AIDS initiative cannot be sustained without the strong involvement of senior management. What has contributed to the support of management has been their own experience of death among their workers, a government policy that decrees that employees must have AIDS education in the workplace, and tangible evidence of project success. Early study findings showed a reduction in the frequency of visits to the clinic by workers and a reduction in STD cases. Later findings revealed that new HIV infections were 34 percent lower among workers in factories where the peer education program was operating compared to a control group (Katzenstein et al. 1998).

\section{Evaluation and Operations Research}

Needs assessment informants were extremely interested in conducting and being exposed to research findings that assess the effectiveness and cost-effectiveness of peer education programs, including longitudinal studies to evaluate the audience's adoption and maintenance of HIV-protective behaviors over 
time. They also expressed a strong interest in comparative studies to measure the effect of peer education in combination with or as compared to other HIV prevention strategies. Informants were also interested in research that answered such operational "how to" questions as how to effectively influence policy makers and stakeholders; how to best select, train, and supervise peer educators; how to address gender and cultural factors; how to scale up programs; and how to sustain peer education activities. In addition, how to operationalize and measure specific variables such as peer educator job performance and couple communication were mentioned as research challenges. Many respondents discussed the need for and challenge of implementing an adequate monitoring and evaluation system that measures both peer education program progress and impact. Informants felt that donors often did not provide any or adequate funds for the evaluation of their peer education programs and discussed the need for additional training, funding, and technical assistance in the area of evaluation design, methods, and analyses.

As noted previously in this paper, there is a lack of rigorously evaluated HIV/AIDS peer education programs in the literature. More commonly found are studies that measure success in terms of program outputs or process indicators, such as the number of peer educators trained, the number of people reached, and the number of condoms distributed. With regard to monitoring and evaluation, the literature review did uncover a few descriptions of more comprehensive and innovative methodologies being used to assess peer education programs. For example, the Southern African Training (SAT) network has designed a planning, monitoring, and evaluation framework used to track inputs, outputs, unit costs, coverage, and the behavioral and biomedical impact of peer education programs. The framework has been applied to over 40 peer education projects in the region enabling the documentation of process and impact indicators in the participating projects (Dube et al. 1998). The use of social network analysis in the evaluation of peer education programs is another example of an innovative methodology that has been applied in youth programs in Ghana and Thailand to address process issues such as recruitment, supervision, retention, initiation and intensity of contacts, quality/accuracy of information, referrals to other services, and coverage/range of efforts (Bond and Wolf 1998; Wolf 1998). The lack of published information on different types of innovative and feasible evaluation methodologies that can be used by HIV/AIDS peer education programs also signifies an important gap to be addressed in future research efforts. 
Although almost all consultation participants stated that their program uses peer education because it is perceived to be an effective strategy, not all programs had collected outcome data to support this hypothesis. Given this situation, many consultation participants felt that more high-quality, rigorous studies to document the effectiveness and costeffectiveness of peer education are needed to sustain donor funding and help improve programs. Several participants suggested a multi-site field trial to assess the impact of integrating the program recommendations formulated by consultation participants into existing peer education programs for a given population group. In addition, participants highlighted the need for comparable process and outcome indicators (and thus data collection instruments) to be used to strengthen program evaluation across countries and program sites. Participants suggested that these indicators should not be limited to HIV-related knowledge and attitudes but also include a range of variables, including behavioral and biomedical outcome indicators.

Consultation participants proposed a number of research questions for each of the nine topical areas (see Appendix 3). Some of these questions pertain to the design of peer education programs and can be answered through diagnostic or formative research using qualitative and quantitative methods.

Example of these questions include:
What is the organization's capacity to integrate or link with additional programs and services?

What are the opportunities and limitations for the HIV-positive peer educator in providing or facilitating care and support for people living with or affected by HIV/AIDS?

Who are the critical stakeholders that may affect program implementation and behavior change in the intended audience? What contributions can these stakeholders make to the peer education program?

\begin{abstract}
A second set of research questions are operational "how to" questions and pertain to program implementation. These questions could be answered through retrospective case studies or through the ongoing collection of qualitative and quantitative data from peer educators and the intended audience via interviews, group discussions, and observation. The following are examples of this type of research question:
\end{abstract}

How can peer education programs increase understanding about the social construction of gender and sexuality relevant to HIV/AIDS among peer educators and their intended audience?

How can stakeholders be engaged not only as facilitators of peer education 
program implementation, but also as facilitators of behavior change in the intended audience?

How can PLHA be motivated and supported to become and continue as peer educators?

A third set of research questions proposed by consultation participants focused on program outcomes and impact. These questions pertain to measuring the effectiveness of program activities on the peer educator (e.g. job performance), the intended audience (e.g. reduction in risk behaviors and STI/ HIV incidence), and on the overall program (e.g. sustainability). Answering these questions involves the use of experimental or quasiexperimental research designs, and qualitative and quantitative methods. The following are examples of research questions that focus on program outcomes and impact and have global significance:

What is the cost-effectiveness of integrating additional services into peer education programs compared to stand-alone peer education programs? What is the effect of integration on peer educator job performance and on the program's acceptability, and quality?

What is the cost-effectiveness of incorporating economic incentives (e.g. condom sales, microcredit) into peer education programs on the retention of peer educators, their job performance, and program sustainability?

What are the health and psychosocial effects on PLHA of training and supporting them as peer educators?

What are the effects on PLHA reached by the peer education program?

These questions generated by consultation participation highlight the diversity of research needs and the importance of generating further information that can be used to strengthen peer education programs. With regard to operations research, consultation participants recommended the following:

- Donors should provide sufficient funds for evaluating PE programs and building local capacity for monitoring and evaluation.

- PE program evaluation should be ongoing and participatory and include formative research, monitoring of program progress, and program impact/effectiveness.

- Both external and internal evaluations should be conducted to ensure program improvement.

- Rigorous studies that use experimental or quasi-experimental designs and HIV-related risk behavior and STI/HIV incidence as outcome measures should be conducted to document the effectiveness of PE in order to ensure continued donor funding. 


\section{Conclusion}

The process of conducting a needs assessment and literature review to identify topics of concern to program managers and peer educators worked well for developing the consultation agenda on HIV/AIDS peer education. Bringing together representatives from a wide range of peer education programs enabled consultation participants to share ideas across continents and cultures, deepen their understanding of critical programmatic issues, and affirm what they are doing well and what they need to do to strengthen their programs. Program managers and peer educators alike stated their commitment to broadening peer education from a strategy that focuses on providing information to one that addresses the diversity of behavior change determinants through expanded dialogue, community mobilization, policy advocacy, and the provision of HIV-related services.

During the consultation, an important area of discussion focused on how to move peer education programs from imparting HIV/AIDS information alone to fostering and sustaining behavior change in their intended audience. Consultation participants highlighted that effective behavior-change communication involves more than "health talks" by the peer educator, but rather entails a variety of approaches to engage the intended audience in reflection and discussion, such as street theater, group problem solving, and radio call-in shows. Peer education also generates demands for other services critical to the behavior change process such as STI management, access to condoms, and HIV counseling and testing. Moreover, they emphasized that broader community development initiatives are needed to reduce structural barriers to HIV prevention. Therefore, peer education programs need to think strategically about either undertaking complementary services and activities that would be led by the peer educator or linking up with ongoing health and development efforts. Whether these additional initiatives are peer educator-led or peer educator-linked will depend on their acceptability to peer educators and the availability of program and community resources.

The needs assessment and the consultation also brought out the issue of the actual cost of peer education programs. Peer education is regarded by some as an inexpensive intervention strategy because it often relies on volunteers. Yet, as consultation participants emphasized, the costs of implementing highquality peer education can be high due to the ongoing need for funds to adequately train, support, supervise, and equip peer educators 
with resource material. In addition, all consultation participants recognized the need for some kind of compensation for peer educators - either a modest salary or non-cash incentives such as t-shirts, bicycles, or free medical care - all of which are costs for the program. While generating resources for peer educator compensation as well as training, supervision, and materials development is a challenge for peer education programs, this project found some examples of promising approaches to address the issue of sustainability. For instance, a number of program managers talked about how they generated resources and support from key stakeholders. One program representative mentioned providing peer educators with credit and then using the interest from the loans to continue offering this incentive to other peer educators. Another program manager noted that they were able to attract new donors because the peer education program was rigorously evaluated and found to be effective. Peer education programs need access to information about these approaches in order to apply them to their situation.

Clearly an important link between program effectiveness and sustainability are the peer educators, particularly their retention and job performance. The peer educators who attended the consultation highlighted the fact that compensation is not the only factor that affects retention and quality of their work.
They cited the importance of involving peer educators in decision-making and giving them broader responsibilities related to program design, implementation, and evaluation. They also called for support mechanisms to address stress and burnout as well as opportunities for personal and professional growth.

An important finding from the documentation process and the consultation was the lack of information and experience on how peer education programs can address the growing need for care and support services for people living with and affected by HIV/AIDS. Given the relationship between prevention and care as well as increasing levels of morbidity and mortality, the need for an appropriate response by peer education programs will only increase. Consultation participants spoke about the importance of defining and documenting appropriate roles for peer educators who are PLHA in different contexts and having access to training and educational materials on care and support of HIV-infected and -affected persons.

Another key point that emerged from discussions with peer educators and program managers is that there are limitations to per education that need to be considered when planning how to intervene with certain audiences. For example, peers (e.g., persons of the same age and class) may not always be the most influential people to promote 
behavior change on certain topics. Therefore, the influence of status, power, and rank must be considered when designing programs. Also important are concerns about safety in places where peer educators may be challenging entrenched power relationships and the maintenance of confidentiality by peer educators who may be privy to sensitive information about their peers. These factors must be considered when deciding the roles and preparation of peer educators and the availability of other human resources to complement the work of peer educators.

As a result of analyzing peer education program accomplishments and obstacles from the research literature and field experiences, this project produced a set of recommendations designed to address program opportunities and challenges. Several of these recommendations are not specific to peer education programs (for example, those that address gender and sexuality) but are applicable to many other types of HIV interventions. For a number of issues specific to peer education, such as compensation, selection, and training of peer educators, there was no clear consensus about what program managers should specifically do. Instead, what emerged was that it's importance for program managers to take into account the sociocultural context and the specific role the peer educator can and will play when making such decisions.
In addition to program recommendations, consultation participants came up with a number of future research directions.

It was clear that more operations research is necessary to move the field forward by providing answers to key "how to" questions, such as: "How can peer education programs meet the gender-specific needs of women and men and also promote gender equity?" and questions about effectiveness, such as "What are the health and psychosocial effects on PLHA of a program that trains and supports PLHA as peer educators?" Consultation participants also felt the need to evaluate programs in different countries that take into account the recommendations for each of the nine topics, using comparable outcome measures in order to provide further evidence of the effectiveness of peer education programs. In addition, new communication mechanisms, such as the formation of an electronic network of peer education programs, are needed in order to foster continued dialogue and exchange and to provide input to decision-making about future operations research.

To accomplish these research, program, and communication goals, continued funding by donors and governments is needed. Project participants strongly felt that such investments are critical to ensure progress in controlling the HIV/AIDS epidemic and mitigating its effects on families and communities. 


\section{References}

AIDSCAP. (1996). "A report of the Peer Education Pre-conference Workshop," IX International Conference on AIDS and STDs in Africa. Kampala, Uganda.

Amaro, O. (1995). "HIV/AIDS Prevention Program Evaluation Report," Prepared for the Massachusetts Primary Prevention Group and the Massachusetts Department of Public Health. Boston, MA.

Bandura, A. (1986). Social Foundations of Thought and Action: A Social Cognitive Theory. Englewood Cliffs, NJ: Prentice Hall.

Bond, K. and Wolf, C. (1998). "Social network and peer promotion programs: Methodological advances," American Public Health Association Conference, November 1998.

Busayawong, W., Cash, K., Chuamanochan, P., and Sanguansermsri, J. (1996). "HIV/AIDS peer education for Northern Thai single migratory female and male adolescent factory workers," XI International Conference on AIDS, Vancouver.

Cash, K., Sanguansermsri, J., and Busayawong, W. (1997). AIDS Prevention through Peer Education for Northern Thai Single Migratory Factory Workers. Washington, DC: International Center for Research on Women.

Coates, T. and Collins, P. (1997). HIV Prevention: A 10-point program to protect the next generation. UCSF AIDS Research Institute and Center for AIDS Prevention Studies (CAPS), Department of Medicine. University of California, San Francisco.

Dube, N., Kathuria, R., Sabatier, R., Chirenda, P., and Wilson, D. (1998). “A peer education project evaluation schema: Inputs, outputs, unit costs, coverage and behavioral impact and biomedical impact," XII International Conference on AIDS, Geneva.

Figueroa, W., Tran, T., Losser, P., and Correll, P. (1998). "Training people living with HIV infection for a community-based care program in Ho Chi Minh City, Vietnam," XII International Conference on AIDS, Geneva.

Fishbein, M. and Ajzen, I. (1975). Belief, Attitude, Intention and Behavior: An Introduction to Theory and Research. Reading, MA: Addison-Wesley.

Flanagan, D., Williams, C. and Mahler, H. (1996). Peer Education in Projects Supported by AIDCSAP: A Study of Twenty-one Projects in Africa, Asia and Latin America. AIDSCAP/ FHI.

Flanagan, D. and Mahler, H. (1996). How to Create an Effective Peer Education Project: Guidelines for Prevention Projects. AIDSCAP/FHI.

Freire, P. (1970). Pedagogy of the Oppressed. New York: Seabury Press. 
Gifford, A., Laurent, D., Gonzales, V., Chesney, M., and Lorig, K. (1998). "Pilot of randomized trial of education to improve self-management skills to men with symptomatic HIV/AIDS." Journal of Acquired Immune Deficiency Syndrome and Human Retrovirology. 18(2): 136-44.

Kathuria, R., Chirenda, P. Sabatier, R., Dube, N. (1998). Peer education to reduce STI/HIV transmission in Lusaka, Zambia. XII International Conference on AIDS, Geneva.

Katzenstein, D., McFarland, W., Mbizvo, M., Latif, A., Machekano, R., Parsonnet, J., and Bassett, M. (1998). Peer education among factory workers in Zimbabwe: providing a sustainable HIV prevention intervention. XII International Conference on AIDS, Geneva.

Kelly, J., Murphy, D., Sikkema, K., McAuliffe, T., Roffman, R., Solomon, L., Winett, R., Kalichman, S. (1997). "Randomised, controlled, community-level HIV-prevention intervention for sexualrisk behaviour among homosexual men in US cities.” Lancet. Nov 22; 350(9090): 1500-5.

Khan, S. (1997). Perspectives on Males Who Have Sex with Males in India and Bangladesh. London: Naz Foundation.

Latkin, C., Vlahov, D. and Knowlton, A. (1996). Use of indigenous drug users for HIV prevention education among their networks. XI International Conference on AIDS, Vancouver.

Lurie, P., Hintzen, P. and Lowe, R. (1995). "Socioeconomic obstacles to HIV prevention and treatment in developing countries: the roles of the International Monetary Fund and the World Bank." AIDS. 9: 535-546.

Maclaren-Ross, S. and Baker, H. (1998). A training program for HIV/AIDS peer support counselors. XII International Conference on AIDS, Geneva.

Merriam Webster. (1985). New Collegiate Dictionary. Springfield, MA: G \& C Merriam.

Morisky, D., Sneed, C., Tiglao, T., Detels, R., and Liu, K. (1998). Behavioral interventions and their positive effects on STD and HIV prevention. International Conference on Emerging Infectious Diseases.

Nakawunde, G. and Ekwaru, J. (1998). Role of PWAs in promoting positive behavior change. XII International Conference on AIDS, Geneva.

Rietmeijer, C., Kane, K., Simons, P., Corby, N., Wolitski, R., Higgins, D., Judson, F., and Cohn, D. (1996). "Increasing the use of bleach and condoms among injection drug users in Denver: outcomes of a targeted community-level HIV prevention program." AIDS. 10(3): 291-8.

Rogers, E. (1983). Diffusion of Innovations. New York: Free Press.

Rosario, S. (1998). Centro de Orientación e Investigación Integral (COIN) Program Report. Santo Domingo.

Sanchez, L. and Arredondo, M. (1996). Broadening the social base of AIDS prevention among men who have sex with men in the Dominican Republic. XI International Conference on AIDS; Vancouver. 
Schapink, D, Mgalla, M., Plummer, M., and Maswa, M. (1998). Development of a district peer health educator programme in primary schools in Tanzania. XII International Conference on AIDS, Geneva.

Shoemaker, K., Gordon, L., Hutchins, V., and Rom, M. (1998). Educating Others with Peers: Others Do--Should You? Background Briefing Report. Georgetown Public Policy Institute, Georgetown University.

Silva, T. et al. (1997). Youth and Sexual Risk in Sri Lanka. Washington, DC: International Center for Research on Women.

Svenson, G. (1998). European Guidelines for Youth AIDS Peer Education. Department of Community Medicine, Lund University, European Commission.

Sweat, M. and Denison, J. (1995). "Reducing HIV incidence in developing countries with structural and environmental interventions." AIDS. 9 (suppl A): S251-S257.

Tawil, O., Verster, A. and O'Reilly, K. (1995). "Enabling approaches for HIV/AIDS prevention: can we modify the environment and minimize the risk?" AIDS. 9: 1299-1306.

Tietz, D., Hatchett, J., Kim, L., Summers, D., Pedraza, J., Castro, D., Brean, W., and Woods, R. (1998). A peer-centered leadership development program for people living with HIV/AIDS: New York State PWS Leadership Institute. XII International Conference on AIDS, Geneva.

UNAIDS. (1998). Technical Update: Gender and HIV/AIDS. Geneva.

Upadhyay, P. (1998). HIV/AIDS/STD education and prevention for military personnel in Nepal. XII International Conference on AIDS, Geneva.

Valdiserri, R., Lyter, D., Leviton, L., Callahan, C., Kingsley, L., and Rinaldo, C. (1989). “AIDS prevention in homosexual and bisexual men: results of a randomized trial evaluating two risk reduction strategies." AIDS. 3(1): 21-6.

Vasconcelos, A., Garcia, V., Mendonça, M.C., Pacheco, M., Braga Pires, M.G., Tassitano, C., and Garcia, C. (1997). Sexuality and AIDS Prevention among Adolescents in Recife, Brazil. Washington, DC: International Center for Research on Women.

Visrutaratna, S., Lindan, C., Sirhorachai, A., and Mandel, J. (1995). “'Superstar' and 'model brothel': developing and evaluating a condom promotion program for sex establishments in Chiang Mai, Thailand." AIDS. 9 (suppl 1): S69-S75.

Wallerstein, N. (1988). "Empowerment education: Freire's ideas adapted to health education." Health Education Quarterly. Winter; 15(4): 379-94.

Weiss, E. and Rao Gupta, G. (1998). Bridging the Gap: Addressing Gender and Sexuality in HIV Prevention. Washington, DC: International Center for Research on Women.

Wolf, C. (1998). Social Network in Adolescent Peer Promotion Programs: Developing Methods for Monitoring and Evaluation. Program Report submitted to CEDPA. 


\section{APPENDIX 1: Consultation Agenda}

\begin{tabular}{|c|c|c|}
\hline Date and time & Activity & Facilitator/Presenter \\
\hline SUNDAY, APRIL 18 & & \\
\hline $\begin{array}{l}\text { 1:30-5:00 p.m. } \\
\text { (optional activity) }\end{array}$ & $\begin{array}{l}\text { Open House in the Negril Suite of } \\
\text { the hotel: informal exchange of } \\
\text { peer education program materials, } \\
\text { videos, and experiences }\end{array}$ & Planning Committee Members \\
\hline 5:00-5:30 p.m. & $\begin{array}{l}\text { Pegasus Hotel reception at the } \\
\text { "Talk Of The Town" } 17^{\text {th }} \text { Floor }\end{array}$ & Kwame Asiedu, HORIZONS \\
\hline 5:30-6:30 p.m. & $\begin{array}{l}\text { Welcome, opening remarks and } \\
\text { keynote address (Talk of the } \\
\text { Town): }\end{array}$ & $\begin{array}{l}\text { Kwame Asiedu, HORIZONS } \\
\text { Mosina Jordan, Mission Director, } \\
\text { USAID/Jamaica } \\
\text { Werasit Sittitrai, Associate Director, } \\
\text { UNAIDS. } \\
\text { Elaine Murphy, PATH } \\
\text { Deanna Ashley, Principal Medical } \\
\text { Officer, MOH, Jamaica. } \\
\text { Peter Figueroa, Chief Medical } \\
\text { Officer, MOH, Jamaica } \\
\text { (Keynote Address) }\end{array}$ \\
\hline 6:30-7:30 p.m. & $\begin{array}{l}\text { Introductions, expectations of the } \\
\text { meeting, ice breaker, and group } \\
\text { culture }\end{array}$ & $\begin{array}{l}\text { Bunmi Makinwa, UNAIDS \& } \\
\text { Kwame Asiedu, HORIZONS }\end{array}$ \\
\hline 7:30 p.m. & \multicolumn{2}{|l|}{ Dinner on your own } \\
\hline
\end{tabular}

\begin{tabular}{|c|c|c|}
\hline Date and Time & Activity & Facilitator/Presenter \\
\hline \multicolumn{3}{|l|}{ MONDAY, April 19} \\
\hline 8:30-9:00 a.m. & $\begin{array}{l}\text { PE consultation goals, objectives } \\
\text { and expected outcomes; agenda } \\
\text { review; housekeeping } \\
\text { announcements }\end{array}$ & $\begin{array}{l}\text { Bunmi Makinwa \& } \\
\text { Werasit Sittitrai, UNAIDS }\end{array}$ \\
\hline 9:00-10:00 a.m. & $\begin{array}{l}\text { Panel: Issues and challenges of PE } \\
\text { programs worldwide } \\
\text { Discussion }\end{array}$ & $\begin{array}{l}\text { Deanna Kerrigan, HORIZONS; } \\
\text { Carol Hooks, PATH; } \\
\text { Gary Svenson, Lund University }\end{array}$ \\
\hline 10:00-11:00 a.m. & $\begin{array}{l}\text { PE as part of other behavior- } \\
\text { change interventions } \\
\text { PE as part of larger HIV/AIDS and } \\
\text { health and development strategies } \\
\text { Discussion }\end{array}$ & $\begin{array}{l}\text { Lovette Byfield, Government of } \\
\text { Jamaica STD/HIV/AIDS Program, } \\
\mathrm{MOH}\end{array}$ \\
\hline 11:00-11:20 a.m. & Coffee and tea break & \\
\hline 11:20 a.m.-12:30 p.m. & $\begin{array}{l}\text { Finding and keeping peer } \\
\text { educators: } \\
\text { Participants' presentations \& }\end{array}$ & $\begin{array}{l}\text { Richard Odindo, The FUTURES } \\
\text { Group International, Kenya } \\
\text { Lediana Marfuru, Iringa NGO } \\
\text { Cluster/Tanzania } \\
\end{array}$ \\
\hline
\end{tabular}




\begin{tabular}{|c|c|c|}
\hline & discussion & $\begin{array}{l}\text { Codou N'Diaye Cisse, } \\
\text { MOE/Senegal } \\
\text { Mahesh Dev Bhattarai, } \\
\text { GWP/Nepal } \\
\text { Nguyen Thanh Son, } \\
\text { ACHCMC/Vietnam } \\
\text { Pedzisani Motlhabane, } \\
\text { University of } \\
\text { Botswana/Botswana } \\
\text { Rosaida Ochoa, MOH/Cuba }\end{array}$ \\
\hline 12:30-2:00 p.m. & Lunch at hotel & \\
\hline 2:00-3:00 p.m. & $\begin{array}{l}\text { 'Take a stand' exercise: } \\
\text { 1) Peer educators as "insiders" vs. } \\
\text { "outsiders"? } \\
\text { 2) Integration of PE in community } \\
\text { life vs. special activities? } \\
\text { 3) Peer education: } \\
\text { accommodating vs. challenging } \\
\text { gender roles? }\end{array}$ & $\begin{array}{l}\text { Werasit Sittitrai, UNAIDS } \\
\& \text { Elaine Murphy, HORIZONS. }\end{array}$ \\
\hline 3:00-3:20 p.m. & Coffee and tea break & \\
\hline 3:20-4:30 p.m. & $\begin{array}{l}\text { Training and support of peer } \\
\text { educators: } \\
\text { Participants'presentations \& } \\
\text { discussion }\end{array}$ & $\begin{array}{ll}\text { Kwame Asiedu, HORIZONS } \\
\text { Richard Bauer, } \\
\text { PASADA/Tanzania } \\
\text { Francisco Cartagena, } \\
\text { Fundeguadalupe/EI Salvador } \\
\text { Richard Odindo, Futures } \\
\text { Group/Kenya } \\
\text { Nadia Badian, SIDC/Lebannon } \\
\text { Richard Olson, } \\
\text { UNICEF/Namibia }\end{array}$ \\
\hline 4:30-5:00 p.m. & Wrap-up; announcements & Bunmi Makinwa, UNAIDS \\
\hline 5 p.m. & \multicolumn{2}{|l|}{ Dinner on your own } \\
\hline
\end{tabular}

\begin{tabular}{|c|c|c|}
\hline Date and Time & Activity & Facilitator/Presenters \\
\hline \multicolumn{3}{|l|}{ TUESDAY, April 20} \\
\hline 8:30-9:30 a.m. & Peer educator panel & $\begin{array}{l}\text { Elaine Murphy, HORIZONS } \\
\text { Carlos Feo, } \\
\text { ComSalud/Venezuela } \\
\text { Jeff Kawana, SFH-PSI//Zambia } \\
\text { Sikha Das, SONAGACHI/India } \\
\text { Mark Scott, Jamaican Red } \\
\text { Cross/Jamaica }\end{array}$ \\
\hline 9:30-10:50 a.m. & $\begin{array}{l}\text { Addressing gender, sexuality and } \\
\text { the sociocultural context: } \\
\text { Participants' presentations \& } \\
\text { discussion }\end{array}$ & $\begin{array}{ll}\text { Deanna Kerrigan, HORIZONS } \\
\square \quad \text { Luis Moreno, COIN/Dominican } \\
\text { Republic } \\
\text { Elizabeth Torres, } \\
\text { GAMI/Columbia } \\
\quad \text { Carol Jenkins, } \\
\text { CARE/Bangladesh } \\
\text { CARtonio Bustamente, } \\
\text { ILPES/Costa Rica }\end{array}$ \\
\hline 10:50-11:10 a.m. & Coffee and tea break & \\
\hline
\end{tabular}




\begin{tabular}{|c|c|c|}
\hline 11:10am-12:30 p.m. & $\begin{array}{l}\text { Activities/content to foster } \\
\text { behavior change } \\
\text { Care and support of PLHA } \\
\text { Participants' presentations \& } \\
\text { discussion }\end{array}$ & $\begin{array}{l}\text { David Wilson, } \\
\text { University of Zimbabwe } \\
\text { Degrando Dipoko, } \\
\text { PSI/Cameroon } \\
\text { Jarolslav Jedlicka, NAP/Czech } \\
\text { Republic } \\
\text { Tan Sokhey, Ministry of } \\
\text { National Defense/Cambodia } \\
\text { Fritz Moise, Fondation pour la } \\
\text { Sante Reproductrice/Haiti } \\
\text { Richard Kirya, Youth } \\
\text { Alive/Uganda }\end{array}$ \\
\hline 12:30-1:50 p.m. & Lunch at hotel & \\
\hline 1:50-3:00 p.m. & $\begin{array}{l}\text { Stakeholder involvement: } \\
\text { Participants' presentations \& } \\
\text { discussion }\end{array}$ & $\begin{array}{ll}\text { Pamela Faura, PSI } \\
\square \quad \text { Porntip Chuamanochan, } \\
\text { Chiang Mai University/Thailand } \\
\text { Verna Mzezewa, } \\
\text { ZAPP/Zimbabwe } \\
\text { Grace Delano, ARFH/Nigeria } \\
\text { Corrie Oosthuzien, } \\
\text { Mpumalanga Prov. Health } \\
\text { Dept./South Africa } \\
\text { Muhammed Siddique, Health } \\
\text { Promotion Society/ Pakistan } \\
\end{array}$ \\
\hline 3:00-3:20 p.m. & Coffee and tea break & \\
\hline 3:20-4:40 p.m. & $\begin{array}{l}\text { Sustainability: } \\
\text { Participants' presentations \& } \\
\text { discussion }\end{array}$ & $\begin{array}{l}\text { Carol Hooks, HORIZONS } \\
\text { Odette Eiger, Femme Face au } \\
\text { SIDA/Cote d'Ivoire } \\
\text { Dr. S. Jana, SONAGHI/India }\end{array}$ \\
\hline 4:40-5:00 p.m. & Wrap-up and announcements & Bunmi Makinwa, UNAIDS \\
\hline 5:00-6:00 p.m. & Free time & \\
\hline 6:00-7:30 p.m. & Group dinner at hotel & \\
\hline 7:30 p.m. & $\begin{array}{l}\text { Performance by ASHE, Jamaican } \\
\text { PE \& theatre troupe }\end{array}$ & Hally Mahler, FHI \\
\hline
\end{tabular}

\begin{tabular}{|l|l|l|}
\hline Date and Time & \multicolumn{1}{|c|}{ Activity } & \multicolumn{1}{|c|}{ Facilitator/Presenters } \\
\hline WEDNESDAY, April 21 & \multicolumn{1}{|c|}{} & \\
\hline 8:30-9:15 a.m. & $\begin{array}{l}\text { Evaluation and operations } \\
\text { research: assessing PE program } \\
\text { effectiveness: } \\
\text { Discussion }\end{array}$ & $\begin{array}{l}\text { Mike Sweat, } \\
\text { Johns Hopkins University }\end{array}$ \\
& Evaluation: & Participants' presentations \& \\
discussion & $\begin{array}{l}\text { Hally Mahler, FHI } \\
\text { anne Palmer, ASEP/Philliplines } \\
\text { George Oppong, Youth } \\
\text { Development } \\
\text { Foundation/Ghana } \\
\text { David Wilson, U. of } \\
\text { Zimbabwe/Zimbabwe } \\
\text { Tamara Fetters, CARE/Zambia }\end{array}$ \\
\hline $10: 30-10: 50$ a.m. & \multicolumn{1}{|c|}{} \\
\hline
\end{tabular}




\begin{tabular}{|l|l|l|}
\hline 10:50-11:00 a.m. & $\begin{array}{l}\text { Assignment of participants to } \\
\text { small groups }\end{array}$ & Carol Hooks, PATH \\
\hline 11:00 a.m. $-12: 30$ p.m. & $\begin{array}{l}\text { Small groups (8) come to } \\
\text { consensus on topical areas (each } \\
\text { group discusses 1 topic): identify } \\
\text { top 3 priorities }\end{array}$ & $\begin{array}{l}\text { 8 facilitators and reporters to be } \\
\text { identified }\end{array}$ \\
\hline 12:30-1:45 p.m. & \multicolumn{1}{|c|}{ Lunch } & Coffee and tea break \\
\hline 1:45-3:15 p.m. & $\begin{array}{l}\text { Small groups report back to whole } \\
\text { group; Discussion }\end{array}$ & Carol Jenkins, CARE/Bangladesh \\
\hline 3:15-3:30 p.m. & $\begin{array}{l}\text { Plenary discussion of priorities } \\
\text { from small groups and } \\
\text { identification of additional priorities }\end{array}$ & $\begin{array}{l}\text { Bunmi Makinwa, UNAIDS \& } \\
\text { Kwame Asiedu, HORIZONS }\end{array}$ \\
\hline 3:30-4:30 p.m. & $\begin{array}{l}\text { Next steps. Review of original } \\
\text { meeting expectations. Thanks to } \\
\text { Jamaican hosts, sponsors, } \\
\text { participants, and planners. }\end{array}$ & $\begin{array}{l}\text { Bunmi Makinwa and Werasit } \\
\text { Sittitrai, UNAIDS; \& Kwame Asiedu, } \\
\text { HORIZONS }\end{array}$ \\
\hline 4:30-5:00 p.m. &
\end{tabular}




\title{
APPENDIX 2: Consultation Participants (alphabetically by region and country)
}

\author{
Africa \\ Motlhabane, Pedzisani \\ AIDS Project Coordinator \\ Community Based AIDS Education \\ U.B. Centre for Continuing Education \\ Box 226 \\ Francistown, BOTSWANA \\ Tel: 267212446 \\ Fax: 267216583 \\ MOTLHABA@NOKA.ub.bw \\ Dipoko Embola Degrando \\ Regional Marketing \& IEC Manager \\ PSI/PMSC \\ P.O. Box 4989 \\ Douala, CAMEROUN \\ Tel/Fax: 237432926 \\ dipoko_degrando@yahoo.fr \\ Odette Muhondo Eiger \\ President and Coordinator \\ Femme Face au SIDA \\ 04 BP 2113, Abidjan 04 \\ COTE D'IVOIRE \\ Tel: 225412922 or 2430 13/14 \\ Fax: 225243119 or 419414 \\ Odetteig@africaonline.co.ci \\ George Appiagyei Oppong \\ Head of Administration and Finance \\ Youth Development Foundation \\ P. O. Box 4941 \\ Kumasi, GHANA \\ Tel: $\quad 233-51-29185-7$ \\ Fax: 233-51-23622 \\ Ypic@Ighmail.com \\ Odindo, Richard \\ NGO/Training Coordinator \\ Futures Group International, UK \\ P.O. Box 75367 \\ Nairobi, KENYA \\ Tel: 254-2-718135 / 719540 \\ Fax: 254-2-724194 \\ richard@futures.co.ke
}

Richard Olson

Youth Health \& Development Project Officer

UNICEF

P.O. Box 1706

Windhoek, NAMIBIA

Tel: 264-61-229-220

Fax: 264-61-224-413

rolson@unicef.org

Grace Delano

Association for Reproductive \& Family Health 13 Ajayi Osungbekun Street

Ikolaba GRA

P.O. Box 30259

Ibadan, NIGERIA

Tel: 234-(0)2-810 1669; 8100164

Fax: 234-(0)2-810 1669

arfh@skannet.com.ng

N'Diaye, Codou

Conseiller Technique au Cabinet du Ministre

Presidente du Comite Interne de lutte contre le SIDA

Ministere de l'Education Nationale

Rue Calmette

B.P. 4025

Dakar, SENEGAL

Tel: 2218221530

Fax: 2218218930

Corrie Oosthuizen, Deputy Director

Mpumalanga Provincial Health Dept.

PO Box 1179

Bethal 2310

Mpumalanga, SOUTH AFRICA

Tel: 27.17.647.3878/082 3724373

Fax: 27.17.647.4011

Masa@sec.lia.net 
Dr. Richard Bauer

Executive Director, PASADA

PO Box 867

Dar es Salaam, TANZANIA

Tel: (255) (51) 865451

Fax: (255) (51) 865451

rbauer@intafrica.com

Lediana Mafuru

Project Manger

Iringa NGO Cluster

Akiba House

P.O. Box 1056

Iringa, TANZANIA

Tel: 25561702583

Home: 25561720198

Fax: 25561702385

Richard Kirya

Director, Youth Alive

P. O. Box 22395

Kampala, UGANDA

Tel: $\quad 256-41-530600$

Fax: 256 - 41 - 534763

Youalive@infocom.co.ug

Fetters, Tamara

Operations Research Advisor

CARE Zambia

Box 36238

Lusaka, ZAMBIA

Tel: $2601265901 / 8$

Fax: 2601265060

Fetters@zm.care.org

Jeff Kawana

Peer Educator

Society for Family Health (PSI-Zambia)

PO BOX 50770

Lusaka, ZAMBIA

Fax: 260-1-292463

sfh@zamnet.zm

Tel: 260-1-292443
Verna Mzezewa

Peer Education Project Manager

Zimbabwe AIDS Prevention Project (ZAPP)

103 Rotten Row

Harare, ZIMBABWE

Tel: 263-4-770610/11

Fax: 263-4-749865

verna@zappuz.co.zw

David Wilson, Professor

University of Zimbabwe

Psychology Department,

PO Box MP 167

Mount Pleasant, ZIMBABWE

Tel: +263.4 .494256 or 497233

Fax: +263.4 .333 .407 or 263.4335.249

Dwilson@esanet.zw or david@psg.uz.zw

\section{Asia}

Jenkins, Carol

Health and Population Sector Coordinator

CARE, Bangladesh

Road 7/A, House 60

Dhanmondi Dhaka 1209

BANGLADESH

Tel: $\quad 8802-9131881$

Home: $8802-871179$

Fax: $\quad 8802-814183$

Cjenkins@bdmail.net

Sokhey Tan

Chief of HIV/AIDS Unit

Ministry of National Defense

\#10 Russian Blvd.

P.O. Box 2452

Phnom Penh, CAMBODIA

Tel: 855015915230

Phauly@undp.forum.org.kh

Sikha Das

Peer Educator, Sonagachi

8/2 Bhabani Dutta Lane

Calcutta 700073

INDIA

Fax 0091332416283

Sjana@giascl01.vsnl.net.in

Ship@cal.vsnl.net.in 
Dr. Samarit Jana

Dept. of Epidemiology

All India Institute of Hygiene and Public

Health

110 Chittaranjan Avenue

7000073 Calcutta, INDIA

Tel: 91-33-241 6283

ship@cal.vsnl.net.in

Mahesh Dev Bhattarai

Director, General Welfare Pratisthan

P O Box 3245

Kathmandu, NEPAL

Tel: $977-01-422935$

Fax: 977-01-417979

Mdb@gpipc.mos.com.np

Gwp@fhiktm.wlink.com.np

Muhammad Siddique

Health Promotion Society

Eidgah Road

Taxila, PAKISTAN

Tel: 92-596-2501

Anne Palmer

Program Officer

PATH Philippines

3/F 395 Sen. Gil J. Puyat Avenue

1200 Makati

Metro Manila, PHILIPPINES

Tel: (632)895-3201

Fax: (632)899-5561

apalmer@skyinet.net or

apalmer@compuserve.net

Chuamanochan, Porntip

Assoc. Professor, Faculty of Pharmacy

Chiang Mai University

Chiang Mai 50200, THAILAND

Tel: 66-053-944307

Fax: 66-053-222741

Pmpti010@cmu.chianggmai.ac.th

Chunya Busayawong

c/o Porntip Chuamanochan

Faculty of Pharmacy

Chiang Mai University

Chiang Mai 50200, THAILAND

Tel: 66-053-944307

Fax: 66-053-222741

Pmpti010@cmu.chiangmai.ac.th
Dr. Thanh Son Nguyen

University Training Center for Health Care

Professionals (U.T.C)

520 Nguyen Tri Phuong St.

District 10, Ho Chi Min City

VIETNAM

Tel: 84.8.8235050

Fax: 84.8.8229152

Thanhson@hcm.fpt.vn

\section{Mideast}

Nadia Bedran

Coordinator

Soins Infirmiers et Développement

Communautaire

P.O. Box 55391, SINELFIL

Beirut, LEBANON

Tel: 9611482428 or 1485647

Sidc@cnrs.edu.lb or sidc@lb.refer.org

\section{Latin America and the Caribbean}

Elizabeth Torres

Grupo de Autoapoyo a la mujer y al infante

Carrera 42, No. 5C 95

Cali, COLOMBIA

Fax: 575518108

Antonio Bustamante Ledó

Peer Educator, Founder, Project Director

Proyecto Experimental El Salón, ILPES

Apdo 10242-

San José, COSTA RICA 1000

Tel: (506)227-9268/286-3312

Fax: (506)222-39-21

Abledomh@sol.racsa.co.cr

Dra. Rosaida Ochoa Soto

Director

Centro de Educacion y Prevencion de las

ETS/VIH/SIDA

La Habana, CUBA

Tel: 537-31-1606/537-30-2017

Fax: 537-66-2029

Cciets@infomed.sld.cu 


\author{
Luis Moreno \\ Centro de Orientacion e Investigation Integral \\ (COIN) \\ c/ Anibal de Espinosa 352 \\ Villas Agricolas, Santo Domingo \\ DOMINICAN REPUBLIC \\ Tel: 1809 681-1515 \\ Fax: 1809 245-4336 \\ coin@ codetel.net.do \\ Francisco José Cartagena Moran \\ Fundacion para el Desarrollo de Guadalupe \\ (FUNDEGUADALUPE) \\ Blvd. Constitucion, Col. Miranda, Pje E1 \\ Rosal \#7 \\ San Salvador, EL SALVADOR \\ Tel/Fax: 503262 0903/503 228-4562 \\ Dr. Fritz Moise \\ Directeur Executif \\ Fondation pour la Sante Reproductrice et de \\ l'Education Familiale \\ 41 Ave. John Brown \\ B.P. 2550 \\ Port-au-Prince, HAITI \\ Tel: 509 23-7375 / 23-7377 \\ Fax: 509239336 or 217696 (UNFPA) \\ Mark Scott \\ National Youth Officer \\ Jamaica Red Cross \\ Block 28-C208 \\ McIntyre Villa \\ Kingsorn 16, JAMAICA \\ Tel: 876 930-3545 \\ Fax: 876 984-8272 \\ Laughmark@hotmail.com or \\ lovingmark@usa.net \\ Hans-Peter Wiebing \\ Programme Officer for the Caribbean \\ UNAIDS Caribbean Office \\ 19 Keate Street \\ P.O. Box 812 \\ Port of Spain, TRINIDAD \\ Tel: 1868623 7056, ext. 245 \\ Fax: 18686238516 \\ Hans.peter.wiebing@undp.org.tt
}

Carlos Feo

Peer Educator

Communicacion para la Salud

Av. Las Palmas, Res. Rocar

PB-A, La Florida, Caracas 1050

VENEZUELA

Tel/Fax: 582-782-7884

comsalud@ reacciun.ve

\section{Europe and North America}

Jedlicka, Jaroslav

National AIDS Programme Manager

UNAIDS Focal Point

National Institute of Public Health

Srobarova Streeet 48

10042 Prague 10

CZECH REPUBLIC

Tel: 420267082650

Fax: 420267082632

Jdlck@post.cz

Michael Sweat, Ph.D

Johns Hopkins University, SHPH

615 North Wolfe St. Room 5505

Balitmore, MD. 21205 USA

Tel: (410) 614-4536

Fax: (703) 995-0615 Fax

Msweat@jhsph.edu

Gary Svenson

Europeer Manager

Department of Community Medicine

Lund University

Malmö University Hospital

SE-20502 Malmö, SWEDEN

Tel: +46-40-332678

Fax. +46-40-336215

Gary.svenson@smi.mas.lu.se

Chad Martin

Special Assistant to the Director on Youth and HIV Prevention

Centers for Disease Control and Prevention

(CDC)

1600 Clifton Road, MS E-35

Atlanta, GA 30333 USA

Tel: $1404639-5217$

Fax: 1404 639-5260

Cgm8@cdc.gov 


\title{
Host Country Speakers and Participants
}

\author{
Jamaican Ministry of Health \\ Dr. Peter Figueroa \\ Dr. Deanna Ashley \\ Lovette Byfield \\ Norman Hall \\ Pansy Fenon \\ Penny Campbell \\ Audrey Anderson \\ Pearline Lee \\ Shirley Wellington
}

Other Government Offices

Shirley Thomlinson, Jamaica Defense Force

\section{USAID/Jamaica}

Sheila Lutjens

Mosina Jordan

\section{UN/Jamaica}

Jocelyne Josiah

Subregional Advisor for Communication in the Caribbean

\section{Jamaican NGOs}

Lois Hue, Jamaica Red Cross

Jan Lopez, Addiction Alert

Andrea Campbell, National Family Planning

Board

Ainsley Reid, JN+ (Jamaica Network of

Seropositives) 


\section{APPENDIX 3: Proposed Research Questions by Topic}

\section{Program Integration}

- What service-delivery needs do PE programs generate? What barriers to behavior change could be addressed by integrating other services/activities with PE? What is the organization's capacity to integrate or link with additional program components? What are the attitudes of program staff and the intended audience towards program integration?

- What is the effect of program integration on PE program focus, acceptability, and quality?

- What is the effect of program integration on the intended audience's and peer educators' attitudes and behaviors?

- What is the cost and cost-effectiveness of program integration compared to stand-alone PE programs?

\section{Finding and Keeping Peer Educators}

- What are the determinants of peer educator volunteerism?

- What individual and programmatic factors are associated with effective job performance and continuity (e.g., literacy level of the peer educator, compensation, supervision and support)?

- What is the cost-effectiveness of PE programs with salaried versus volunteer peer educators?

\section{$\underline{\text { Training and Supervision }}$}

- What constitutes an effective PE training program (e.g., length of training, curriculum content, training methodology) in terms of peer educator job performance and satisfaction, and behavioral outcomes in the intended audience?

- What constitutes an effective supervision and support program for HIV/AIDS peer educators?

\section{Gender, Sexuality, and the Sociocultural Context}

- What are effective tools and approaches for conducting gender analysis to identify gender bias among peer educators, staff, and the intended audience that may have an impact on HIV prevention, care, and support?

- How can PE programs increase understanding about the social construction of gender and sexuality relevant to HIV/AIDS among peer educators and their intended audience? How 
can PE programs meet the gender-specific needs of women and men and also promote gender equity?

- What is the impact on the intended audience of efforts by peer educators to reduce genderrelated barriers to HIV prevention, care, and support?

\section{$\underline{\text { Program Activities to Foster Behavior Change }}$}

- How can PE programs move from imparting AIDS facts alone to fostering and sustaining behavior change in their intended audience?

- Which peer-led or peer-linked activities (health talks, theater, radio call-in shows, counseling, support groups, advocacy) are effective in facilitating HIV-related behavior change?

- How often (number of contacts/timeframe) should such peer-led activities be implemented?

- What types of knowledge and skills do peer educators need to lead such activities?

\section{$\underline{\text { Care and Support for PLHA }}$}

- What type of training, tools, and resources are needed to effectively equip peer educators to provide and/or facilitate access to care and support to PLHA?

- What are the roles and limitations of the HIV-infected peer educator in providing and/or facilitating care and support to other people living or affected by HIV/AIDS, given concerns about stigma, confidentiality, and health?

- How can PLHA be motivated and supported to become and continue as peer educators?

- What are appropriate outcome indicators for PE programs focused on providing care and support for PLHA?

- What are the health and psychosocial effects on PLHA of a program that trains and supports PLHA as peer educators? What are the effects on PLHA reached by the PE program?

\section{$\underline{\text { Stakeholder Involvement }}$}

- Who are the critical stakeholders that may affect PE program implementation and behavior change in the intended audience? What contribution can these stakeholders make to the PE program (e.g., donate human and/or financial resources, advocate for program implementation)?

- What motivates stakeholder participation and support for the PE program? 
- How can stakeholders be engaged, not only as facilitators of PE program implementation, but also as facilitators of behavior change in the intended audience?

\section{$\underline{\text { Sustainability }}$}

- How can PE programs be marketed in order to procure funding from outside donors (e.g., development of a sustainability plan, documentation of program effectiveness)?

- What income-generation activities are effective in contributing to the sustainability of PE programs (e.g., interest from microcredit loans, clinic fees, condom sales)?

- Does linkages between government and NGOs reduce costs or increase the efficiency of PE programs and thereby contribute to sustainability? 